See discussions, stats, and author profiles for this publication at: https://www.researchgate.net/publication/335023397

\title{
Effect of the curing type on the mechanical properties of lightweight concrete with polypropylene and steel fibres
}

Article in Construction and Building Materials · August 2019

DOI: 10.1016/j.conbuildmat.2019.08.006

CITATIONS

9

4 authors, including:

Mostafa Kazemi

University of Liège

12 PUBLICATIONS 101 CITATIONS

SEE PROFILE

Jorge de Brito

University of Lisbon

1,441 PUBLICATIONS 16,209 CITATIONS

SEE PROFILE

Some of the authors of this publication are also working on these related projects:

Project Sustainable Development of Cement-based Materials: Application to Recycled Aggregates Concrete View project
362

Pouyan Khakpour Talebi

2 PUBLICATIONS 12 CITATIONS

SEE PROFILE 


\title{
Effect of the curing type on the mechanical properties of lightweight concrete with polypropylene and steel fibres
}

\author{
Rahmat Madandoust $^{a}$, Mostafa Kazemi $^{b}$, Pouyan Khakpour Talebic $^{\text {, Jorge de Brito }}{ }^{\mathrm{d}}$ \\ ${ }^{a}$ Associate Professor, Department of Civil Engineering, University of Guilan, P.O. Box 3756, Rasht, Iran, rmadan- \\ doust@yahoo.com \\ ${ }^{\mathrm{b}}$ MSc Graduate Student, Department of Civil Engineering, University of Guilan, Rasht, Iran, \\ kazemi.civil68@gmail.com \\ ${ }^{c}$ MSc Graduate Student, Department of Civil Engineering, Islamic Azad University, Bushehr Branch, Iran, \\ pouyan.khakpour@gmail.com \\ ${ }^{\mathrm{c}}$ Full Professor, CERIS, Department of Civil Engineering. Architecture and Georresources, Instituto Superior Técnico, \\ Universidade de Lisboa, jb @ civil.ist.utl.pt
}

\begin{abstract}
This study assessed the effect of steel and polypropylene fibres at various volume contents on concrete incorporating lightweight expanded clay aggregate (LECA) and water/binder (W/B) ratios of 0.37 and 0.42. The concrete specimens were cured under six curing conditions: wet, 3-day wet, 14-day wet, air-dry controlled, air-dry uncontrolled, and $90{ }^{\circ} \mathrm{C}$ vapour. The use of lightweight aggregates in the construction industry has drawn the attention of researchers and, on the other hand, fibres with a high strain-hardening response can be used as an appropriate addition in concrete materials. In this study, the mechanical properties of lightweight concrete containing steel or polypropylene fibres were evaluated by means of compressive strength, splitting tensile strength and modulus of elasticity tests at 3, 7, 28 and 60 days. According to the results, fibre reinforced concrete mixes containing LECA, cured under $90{ }^{\circ} \mathrm{C}$ vapour curing, achieved the highest mechanical strength. In addition, the optimum contents of steel fibres to obtain the highest compressive and splitting tensile strengths of lightweight concrete were $1 \%$ and $3 \%$, respectively.
\end{abstract}

Keywords: LECA, steel fibres, polypropylene fibres, curing conditions, concrete mechanical properties 


\section{Introduction}

The overuse of natural aggregate in the construction sector has harmed the environment in recent decades, and it is estimated that about 7.5 billion tonnes of aggregates are annually consumed by the concrete industry [1-5]. This environmental issue can be somewhat solved by partial replacement of natural aggregates with artificial lightweight aggregates in the building process [610]. Although the use of lightweight concrete (LC) dates back to the Roman Empire, modern age artificial lightweight aggregates were produced in the middle of the $20^{\text {th }}$ century and then they were developed by researchers in the concrete industry [11, 12]. Of all artificial lightweight aggregates, lightweight expanded clay aggregates (LECA) with a density below $2 \mathrm{~g} / \mathrm{cm}^{3}$ were first used in Scandinavia in 1930 to produce lightweight cubes, and the concept of concrete made with LECA was subsequently analysed by researchers to efficiently reduce the dead load of structure [13-15]. The main differences between natural aggregates and LECA are the greater porosity and water absorption of LECA, which leads to lower mechanical strength of LC [11, 12, 16, 17]. However, using saturated or semi-saturated LECA in concrete positively affected the durability via internal curing [18]. Therefore, the high water absorption of LECA can explain why a poor curing condition can affect the mechanical strength of lightweight concrete more than that of normal weight concrete. Regarding the water absorption of LECA, Ferreira et al. [19] and Saikia and de Brito [20] suggested a pre-saturation method, where the effective water/binder (W/B) ratio can be kept constant by preventing further water absorption of LECA. Concerning the mechanical properties of LECA, Hassan et al. [21] produced three different grades of LECA, and concluded that the finer size of LECA (1-4 mm) caused their agglomeration and a subsequent decrease of the mechanical strength of the concrete specimens. A porosity analysis was performed by Tataranni et al. [22] on LECA with nominal size of 4-16 mm. The results showed that LECA can be classified as a light- 
weight aggregate with smaller pores and well-distributed voids. As per a study by Hubertova and Hela [23], low strength was obtained for concrete mixes made with LECA. Similar results were reported by Hassan et al. [24], where they showed a substantial decrease of the compressive strength by increasing the amount of LECA in the concrete mixes. The hydration process of concrete containing lightweight aggregates was evaluated by Mindess et al. [25], and the inner relative humidity was suggested to stay at about $80 \%$ so that the chemical reaction and hydration rate effectively increased. They also concluded that, by considering W/B ratio less than 0.36 , the inner relative humidity of the concrete mix cannot be provided. Espinoza-Hijazin and Lopez [26] conducted a study on concrete containing lightweight aggregate with W/B between 0.4 and 0.5 . They showed that the highest hydration process can be obtained for concrete mixes with W/B ratio of 0.425 .

Concrete is one of most popular construction materials and it has high compressive strength and low tensile strength [27-31]. So, when tensile cracking dominates concrete behaviour, it is required to use appropriate additions with a strain-hardening response under tensile loading [31, 32]. Fibres are known for their tensile strength capacity and they have been widely used to improve the resistance to tensile stress and concrete spalling [33-36]. So, the tensile and flexural strength of concrete materials can be remarkably improved by adding a low volume of fibres, while a moderate increase can occur in the compressive strength of fibre reinforced concrete due to a high strain-hardening response of fibres under tensile loading. Meanwhile, the increase in splitting tensile strength, flexural strength and toughness index for LC seems much higher than that of normal aggregate concrete owing to better interlocking between fibres and lightweight aggregates than normal aggregates $[37,38]$. Among available fibres, polypropylene fibres (PF) can generate a suitable bond quality between aggregates and cement particles. Aulia [39] showed that PF decreased the early plastic shrinkage cracking and improved the ductility behaviour and 
tensile capacity of high-strength concrete by providing bridging forces across cracks. Similar results were reported by Banthia and Gupta [40]. They showed that PF controlled plastic shrinkage cracking. Meanwhile, longer PF appeared to be highly effective in preventing cracks propagation. Fallah and Nematzadeh [41] showed that the cohesion and bond, provided by PF in plain concrete, led to a decrease in slump. They assessed the mechanical properties of concrete containing PF at $0.1-0.5 \%$ by volume, where only $0.1 \%$ PF had a positive effect on the compressive strength of concrete. In addition, concrete's tensile strength and modulus of elasticity increased by increasing the volume of PF from $0.1 \%$ to $0.3 \%$, while the reverse occurred for higher contents. Similarly, Zhang et al. [42] recently recommended using a suitable amount of PF to enhance the impact toughness and mechanical strength of concrete. Another type of fibres is steel fibres (SF), with a higher tensile strength than PF. SF can increase the compressive strength of concrete by changing the direction of cracks, which leads to reducing the stress concentration at the tip of cracks and subsequently delaying the failure of concrete elements as described by Yan et al. [43]. The mechanical properties of concrete with SF at $0.25-2 \%$ by volume were assessed by Mohod [44]. The results showed that SF caused the slump of concrete mixes to decrease. Meanwhile, concrete mixes incorporating SF at $0.75 \%$ and $1 \%$ by volume were considered optimum mix designs in terms of maximizing the flexural and compressive strengths. Afroughsabet and Ozbakkaloglu [45] evaluated the mechanical properties of high-strength concrete incorporating SF at $0.25 \%$ and $1 \%$ by volume, where the highest splitting tensile and flexural strengths were obtained for concrete incorporating $1 \%$ SF. To compare the effect of curing conditions on the tensile strength of fibre reinforced geopolymer composite containing SF and PF, Bhutta et al. [46] showed that the heat curing improved much more the tensile strength of fibre reinforced geopolymer composite containing SF than that of the one containing PF, owing to higher re- 
sistance of SF than PF to higher curing temperature.

So, it seems that the mechanical strength of LC can be improved by using fibres. The effect of SF on the mechanical properties of LC was assessed by Shafigh et al. [47]. They revealed that the increase in compressive strength of LC with SF was higher at older ages than at early ages, owing to the better cohesion and stronger bond between the fibres and the matrix at older ages. Furthermore, the addition of SF reduced the sensitivity of LC to poor curing condition. In another study, the mechanical properties of LC with SF at $0.25-1 \%$ by volume were assessed by Hassanpour et al. [48]. The results showed that $1 \%$ incorporation of SF increased the tensile strength of LC up to $77 \%$ by bridging the cracks and subsequently delaying the growth rate of tensile cracks. Zohrabi et al. [49] conducted a limited study on the compressive strength of LC containing $1 \%$ of SF and PF. They observed that there was no significant enhancement in the compressive strength of LC by adding $1 \% \mathrm{PF}$, while $1 \%$ SF remarkably increased this property. For further investigation, the present study is an effort to assess the effect of $\mathrm{SF}$ and $\mathrm{PF}$ at various volume contents on the mechanical properties of concrete incorporating LECA with W/B ratios of 0.37 and 0.42 at 3, 7, 28 and 60 days. Since the curing regime and age can affect the mechanical properties of concrete materials [50-55] and wet curing condition appear to be highly effective in improving the compressive strength of fibre reinforced concrete (FRC) and LC [56, 57], cubic and cylindrical specimens were cured under six curing conditions: wet, 3-day wet, 14-day wet, air-dry controlled, air-dry uncontrolled, and $90^{\circ} \mathrm{C}$ vapour. Therefore, the concrete specimens were cured by immersion in a water tank and taken out after different ages; then, the results of these specimens were compared with those cured under $90{ }^{\circ} \mathrm{C}$ vapour curing condition. In addition, other concrete specimens were kept in lab condition (air-dry controlled cuirng regime) and open air without any control (air-dry uncontrolled curing regime); thereafter, their results were compared. A combination of the methods was 
used to obtain variations of splitting tensile strength and modulus of elasticity vs. compressive strength and propose one-variable equations under different curing conditions. Meanwhile, correlation curves were obtained between modulus of elasticity and compressive strength, and they were compared with those of ACI 318 [58].

\section{Experimental program}

\subsection{Materials}

In this study, type II Portland cement was used with a density of $3.2 \mathrm{~g} / \mathrm{cm}^{3}$ and surface area of $3055 \mathrm{~cm}^{2} / \mathrm{g}$. Table 1 shows the chemical composition of this type of cement. The density and water absorption of crushed gravel, used in concrete mixes, were equall to $2.65 \mathrm{~g} / \mathrm{cm}^{3}$ and $1.1 \%$, respectively. The corresponding values for natural river sand were $2.84 \mathrm{~g} / \mathrm{cm}^{3}$ and $3.5 \%$. The size grading curves of crushed gravel and natural river sand are within the ranges given by ASTM C33 [59] as shown in Fig. 1. LECA, with a nominal size of 3-15 mm, was provided from Iran LECA company, located in Saveh, as shown in Fig. 2. Table 1 shows the chemical composition of LECA, with a density of $0.545 \mathrm{~g} / \mathrm{cm}^{3}$ and water absorption of $18 \%$. A superplasticizer of polycarboxylic ether-type, suited for improving the workability of concrete, was provided from the Feroplast Company and added to the mixes as proposed by other researchers [60-62]. As suggested by Fallah and Nematzadeh [41], PF with diameters of $0.1 \mathrm{~mm}, 0.2 \mathrm{~mm}$, and $0.3 \mathrm{~mm}$, were added to the concrete mixes, as indicated in Fig. 3(a). The density and tensile strength of PF were equal to $0.91 \mathrm{~g} / \mathrm{cm}^{3}$ and $400 \mathrm{MPa}$, respectively. As shown in Fig. 3(b), hooked-end SF with diameters of $1 \mathrm{~mm}, 2 \mathrm{~mm}$, and $3 \mathrm{~mm}$ were used. The length, density, and tensile strength of hooked-end SF were $50 \mathrm{~mm}, 7.61 \mathrm{~g} / \mathrm{cm}^{3}$, and $809 \mathrm{MPa}$, respectively. 
Table 1. Chemical composition of the Portland cement and LECA

\begin{tabular}{ccc}
\hline $\mathrm{XRF}$ & Cement $(\%)$ & LECA (\%) \\
\hline $\mathrm{SiO}_{2}$ & 22.45 & 66.05 \\
$\mathrm{Al}_{2} \mathrm{O}_{3}$ & 4.85 & 16.57 \\
$\mathrm{Fe}_{2} \mathrm{O}_{3}$ & 3.95 & 7.10 \\
$\mathrm{CaO}$ & 64.81 & 2.46 \\
$\mathrm{MgO}$ & 0.8 & 1.99 \\
$\mathrm{SO}_{3}$ & 0.85 & - \\
$\mathrm{Na}_{2} \mathrm{O}$ & 0.25 & 0.69 \\
$\mathrm{~K}_{2} \mathrm{O}$ & 0.51 & 2.69 \\
$\mathrm{C}_{3} \mathrm{~A}$ & 7.1 & - \\
$\mathrm{LOI}$ & 0.25 & - \\
$\mathrm{TiO}_{2}$ & - & 0.78 \\
$\mathrm{P}_{2} \mathrm{O}_{5}$ & - & 0.21 \\
$\mathrm{MnO}$ & - & 0.09 \\
\hline
\end{tabular}

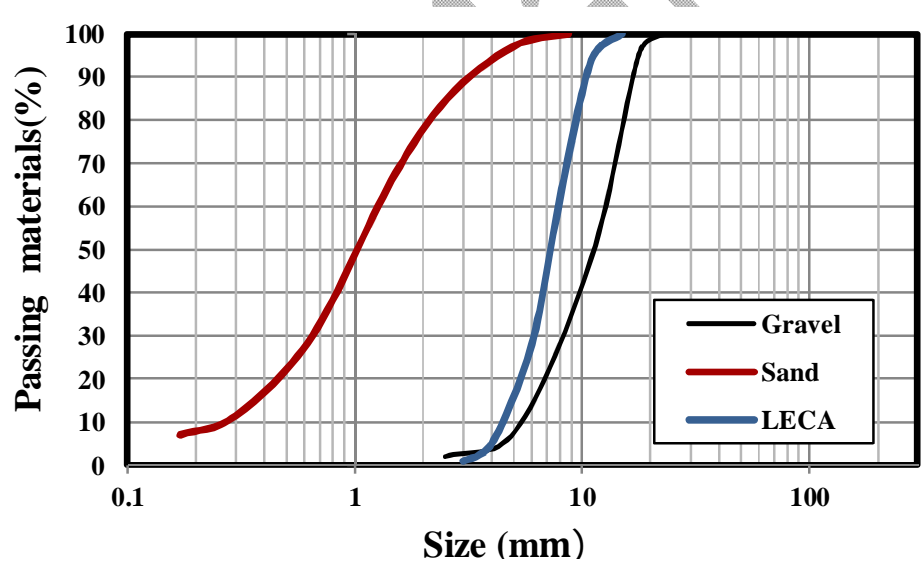

Fig. 1. Aggregates' size distribution

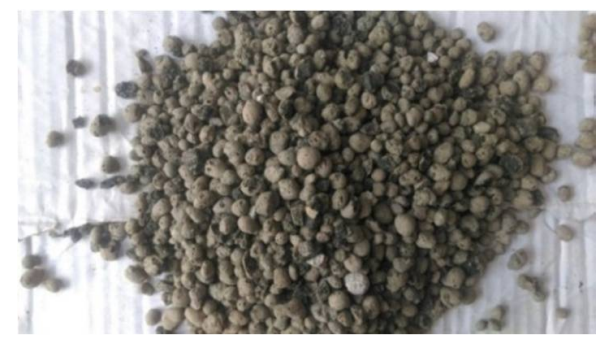

Fig. 2. LECA used in the concrete mixes 


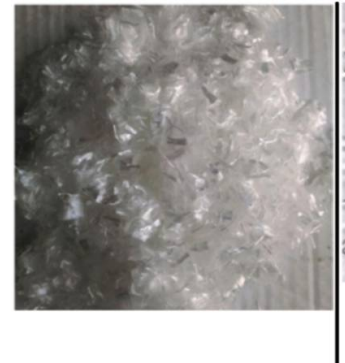

(a)

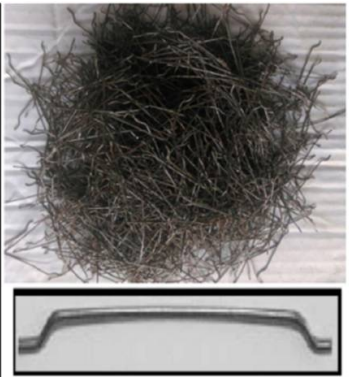

(b)

Fig. 3. PF (a); Hooked-end SF (b)

\subsection{Mix proportioning}

As seen in Table 2, 14 concrete mix designs were made in the present study. Regarding the W/B ratio, Mindess et al. [25] concluded that, by considering a W/B ratio less than 0.36 , the inner relative humidity of LC mixes cannot be provided. In addition, Zohrabi et al, [49] observed that, by considering a W/B ratio of 0.37 in concrete mixes with LECA and PF and SF, a suitable compressive strength can be obtained. Meanwhile, a study by Espinoza-Hijazin and Lopez [26] on LC with W/B ratio between 0.4 and 0.5 showed that the highest hydration process can be obtained for mixes with a W/B ratio of 0.425 . So, in this study, the effective $\mathrm{W} / \mathrm{B}$ ratios were considered to be 0.37 and 0.42 . All aggregates were used in the saturated surface-dry condition to prevent further water absorption. Since LECA can effectively reduce the compressive strength of concrete, the coarse natural aggregates were only replaced at $30 \%$ with LECA to achieve appropriate mechanical properties of concrete.

For mix preparation, the sand, and coarse natural aggregate and LECA were first mixed for $30 \mathrm{~s}$ at normal speed. Then, half of the tap water was added into the mixer and mixing went on for 1 min. Thereafter, cement was added and mixed for one more minute. Then, the fibres, along with the remaining water and superplasticizer, were intermittently and slowly introduced in the mixer, and mixing went on for $3 \mathrm{~min}$. This procedure prevented clustering of the SF and PF and thoroughly distributed them in the concrete mass as advised by Hemmati et al. [63]. Finally, $15 \mathrm{~cm}$ cubes samples were 
made to determine 3-, 7-, 28-, and 60-day compressive strength based on ASTM C39 [64]. Meanwhile, $15 \times 30 \mathrm{~cm}$ cylindrical samples were cast to obtain $3-, 7-, 28-$ and 60 -day splitting tensile strength and modulus of elasticity as per ASTM C496 [65] and ASTM C469 [66], respectively. In addition, the loading rate of the compressive and tensile testing was $0.5 \mathrm{MPa} / \mathrm{s}$ according to European standard EN 12390-13 [67].

Table 2. Mix details

\begin{tabular}{|c|c|c|c|c|c|c|c|c|c|}
\hline Mix ID & $\mathrm{SF}(\%)$ & $\mathrm{PF}(\%)$ & $\begin{array}{l}\text { Cement } \\
\left(\mathrm{kg} / \mathrm{m}^{3}\right)\end{array}$ & $\begin{array}{l}\text { Water } \\
\left(\mathrm{L} / \mathrm{m}^{3}\right)\end{array}$ & $\begin{array}{c}\text { Coarse } \\
\text { aggregate } \\
\left(\mathrm{kg} / \mathrm{m}^{3}\right)\end{array}$ & $\begin{array}{c}\text { Fine } \\
\text { aggregate } \\
\left(\mathrm{kg} / \mathrm{m}^{3}\right)\end{array}$ & $\begin{array}{l}\text { LECA } \\
\left(\mathrm{kg} / \mathrm{m}^{3}\right)\end{array}$ & $\begin{array}{l}\text { Superplasticizer } \\
\left(\mathrm{kg} / \mathrm{m}^{3}\right)\end{array}$ & $\mathrm{W} / \mathrm{B}$ \\
\hline Ctrl-L $\mathrm{L}^{\mathrm{a}}$ & - & - & 440 & 162.8 & 350 & 701 & 150 & 1.7 & 0.37 \\
\hline $\mathrm{PF}^{\mathrm{b}} 0.1-\mathrm{L}$ & - & 0.1 & 440 & 162.8 & 350 & 698 & 150 & 2.1 & 0.37 \\
\hline PF0.2-L & - & 0.2 & 440 & 162.8 & 350 & & 150 & 2.65 & 0.37 \\
\hline PF0.3-L & - & 0.3 & 440 & 162.8 & 350 & 692 & 150 & 3.2 & 0.37 \\
\hline $\mathrm{SF}^{\mathrm{c}} 1-\mathrm{L}$ & 1 & - & 440 & 162.8 & & 698 & 150 & 2.6 & 0.37 \\
\hline SF2-L & 2 & - & 440 & 162.8 & 350 & 695 & 150 & 2.89 & 0.37 \\
\hline SF3-L & 3 & - & 440 & 162.8 & 350 & 692 & 150 & 3.3 & 0.37 \\
\hline Ctrl- $\mathrm{H}^{\mathrm{d}}$ & - & - & 440 & 184.8 & 350 & 656 & 150 & 1.5 & 0.42 \\
\hline PF0.1-H & - & 0.1 & 440 & 184.8 & 350 & 652 & 150 & 1.85 & 0.42 \\
\hline PF0.2-H & - & 0.2 & 10 & 184.8 & 350 & 650 & 150 & 2.2 & 0.42 \\
\hline PF0.3-H & - & 0.3 & & 184.8 & 350 & 647 & 150 & 2.89 & 0.42 \\
\hline SF1-H & 1 & 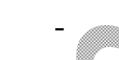 & 440 & 184.8 & 350 & 652 & 150 & 2.2 & 0.42 \\
\hline SF2-H & 2 & & +40 & 184.8 & 350 & 650 & 150 & 2.5 & 0.42 \\
\hline SF3-H & 3 & & & 184.8 & 350 & 647 & 150 & 3.1 & 0.42 \\
\hline
\end{tabular}

${ }^{\mathrm{a}}$ Low W/B ratio $(0.37)$

${ }^{\mathrm{b}} \mathrm{PF}$

${ }^{\mathrm{c}} \mathrm{SF}$

${ }^{\mathrm{d}}$ High W/B ratio $(0.42)$

\subsection{Curing conditions}

Temperature and humidity play a key role on curing concrete specimens in experimental conditions; furthermore, the duration of immersion in water can influence the hardened properties of concrete. So, by considering the fact that curing regimes and ages can affect the mechanical strength of concrete [68-71], the mechanical properties of the concrete specimens were assessed under six curing 
conditions wet, 3-day wet, 14-day wet, air-dry controlled, air-dry uncontrolled, and $90{ }^{\circ} \mathrm{C}$ vapour in which the concrete specimens were demoulded after $24 \mathrm{~h}$. It is noteworthy that the concrete specimens were cured by immersion in a water tank and taken out after different ages (wet, 3-day wet and 14-day wet curing conditions); then, the results of these specimens were compared with those cured under $90{ }^{\circ} \mathrm{C}$ vapour curing condition to assess the effect of vapour and wet curing conditions at different ages on the mechanical properties of concrete specimens. In addition, other concrete specimens were kept in lab condition (air-dry controlled curing regime) and open air without any control (air-dry uncontrolled curing regime) and their results were compared to each other.

\subsubsection{Wet curing condition}

In this curing regime, after demoulding, the concrete specimens were cured by immersion in a water tank at $24{ }^{\circ} \mathrm{C}$ up to the time of testing.

\subsubsection{3-day wet curing condition}

In this curing type, after demoulding, the concrete specimens were cured by immersion in a water tank and taken out after 3 days. Then they were kept under lab conditions until the date of testing.

\subsubsection{4-day wet curing condition}

After demoulding, the concrete specimens were cured by immersion in a water tank and taken out after 14 days. Then they were kept under lab until the date of testing.

\subsubsection{Air-dry controlled curing condition}

In this curing condition, after demoulding, the concrete specimens were kept under lab conditions at average humidity of $70 \%$ and $22-24{ }^{\circ} \mathrm{C}$ temperature (Fig. 4). It is noteworthy that a heating ventilation and air conditioning (HVAC) system was used in the laboratory to ensure that the humidity and ambient temperature were within the expected range. 


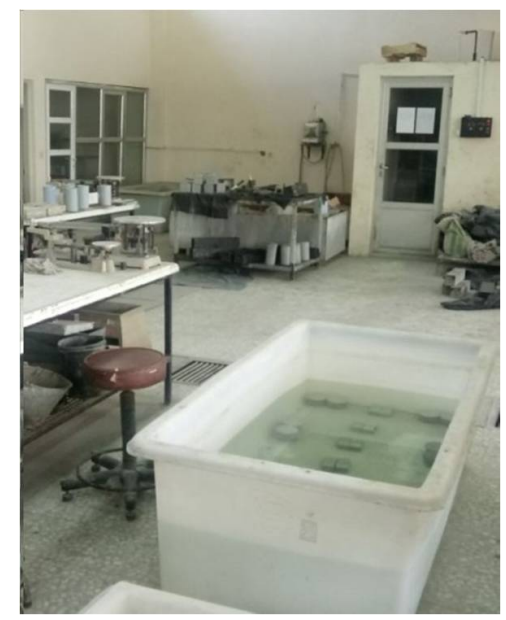

Fig. 4. Laboratory space

\subsubsection{Air-dry uncontrolled curing condition}

In this method, after demoulding, the concrete specimens were kept in open air without any control, i.e. humidity and temperature were variable.

\subsection{6. $90{ }^{\circ} \mathrm{C}$ vapour curing condition}

In this method, there was some water at the bottom of the curing tank. After demoulding, the concrete specimens were kept in the curing system at a temperature of $90{ }^{\circ} \mathrm{C}$, leading to generating the vapour curing condition, while the curing tank was closed as seen in Fig. 5a. Then, the concrete specimens were taken out after 2 days. Later on, they were kept under lab conditions until the date of testing. A cylindrical heater was prepared in the centre of the concrete curing system as shown in Fig. $5 b$ to uniformly distribute the temperature within the concrete specimens.

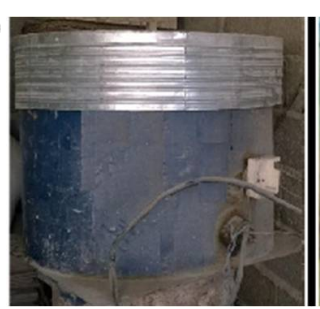

(a)

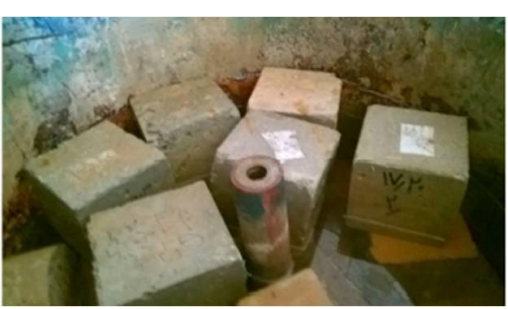

(b)

Fig. 5. Concrete curing system (a); Concrete specimens in the curing system (b) 


\subsection{Sample preparation}

Cube specimens were made to obtain the compressive strength (CS) of concrete under six curing conditions at 3, 7, 28 and 60 days. At each age and curing condition, three concrete specimens were made. Therefore, the results were the average of three $15 \mathrm{~cm}$ cubic specimens, and the total number of cubes was 1008 . The same total number was considered to make cylindrical samples and obtain the splitting tensile strength, where the results were the average of three cylindrical samples. In addition, the modulus of elasticity of cylindrical specimens was determined under six curing conditions at 3, 7, 28 and 60 days. Similarly to the compression test, the results of modulus of elasticity were the average of three specimens, and the total number of cylindrical samples for this test was 1008 .

\section{Results and discussion}

\subsection{Slump}

The slump of the LC control mix with $0.37 \mathrm{~W} / \mathrm{B}$ ratio was found to be $72 \mathrm{~mm}$. A similar study by Hassanpour et al. [48] reported a slump value of $65 \mathrm{~mm}$ for a LC with $0.32 \mathrm{~W} / \mathrm{B}$ ratio. The present study intended all concrete mixes to have an appropriate workability. According to the Fallah and Nematzadeh [41] and Mohod [44] results, the SF and PF caused a reduction of the workability and slump values of the concrete mixes owing to the cohesion and bond between the fibres and the concrete matrix. So, more superplasticizer was added to the mixes when increasing the amount of fibres to maintain a suitable slump. As seen in Table 3, the slump of concrete mixes with W/B ratio of 0.37 was in the $72-76 \mathrm{~mm}$ range. These values for $\mathrm{W} / \mathrm{B}$ ratio of 0.42 were in the $72-77 \mathrm{~mm}$ range. So, the difference between the slump of LC mixes made with fibres and control specimens was negligible due to the adjustment of the superplasticizer's content. On the other hand and as expected, as seen in Table 3, lower amounts of superplasticizer were required 
for the higher W/B ratio (0.42) to achieve the intended workability.

\subsection{Compressive strength}

The CS of LC made with various contents of PF and SF under six curing conditions at 3, 7, 28 and 60 days is shown in Fig. 6. The CS ratios of FRC mixes to control mixes are presented in Table 4. The CS of concrete made with LECA and a W/B ratio of 0.37 under wet curing at 28 days was about $17.4 \%$ more than that at 7 days. The corresponding difference given by Zohrabi et al. [49] was $21 \%$. Since concrete specimens under wet, 3-day and 14-day wet curing conditions were cured by immersion in a water tank at early ages, the CS of the control mixes under these three curing conditions was nearly the same, particularly at early ages (3 days and 7 days) as seen in Figs. 6 (a), (b) and (c). For instance, the CS of concrete with W/B ratio of 0.42 under these curing regimes was about 31.5 $\mathrm{MPa}$ and $35.5 \mathrm{MPa}$ at 3 and 7 days, respectively, while these values under wet curing were on average about $11 \%$ higher than those under 3-day and 14-day wet curing at 28 and 60 days. The corresponding difference for $\mathrm{W} / \mathrm{B}$ ratio of 0.37 was $17.2 \%$.

Table 3. Slump values of concrete mixes

\begin{tabular}{ccc}
\hline Mix ID & Slump $(\mathrm{mm})$ & Superplasticizer $\left(\mathrm{kg} / \mathrm{m}^{3}\right)$ \\
\hline Ctrl-L & 72 & 1.7 \\
PF0.1-L & 73 & 2.1 \\
PF0.2-L & 76 & 2.65 \\
PF0.3-L & 72 & 3.2 \\
SF1-L & 75 & 2.6 \\
SF2-L & 74 & 2.89 \\
SF3-L & 73 & 3.3 \\
\hline Ctrl-H & 75 & 1.5 \\
PF0.1-H & 75 & 1.85 \\
PF0.2-H & 74 & 2.2 \\
PF0.3-H & 72 & 2.89 \\
SF1-H & 77 & 2.2 \\
SF2-H & 75 & 2.5 \\
SF3-H & 72 & 3.1 \\
\hline
\end{tabular}

According to Figs. 6 (b) and (e), the CS of the control mixes under 3-day wet curing was higher than that under air-dry uncontrolled curing, particularly at early ages, while there was no difference 
for these curing regimes at older ages. This may be due to the fact that over time the free water in concrete mixes under air-dry uncontrolled curing evaporated and the trapped water molecules in LECA were given back to the empty capillary pores to react with cement particles and complete the hydration process at older ages (Fig. 7), similarly to what Wang et al. [57] reported.
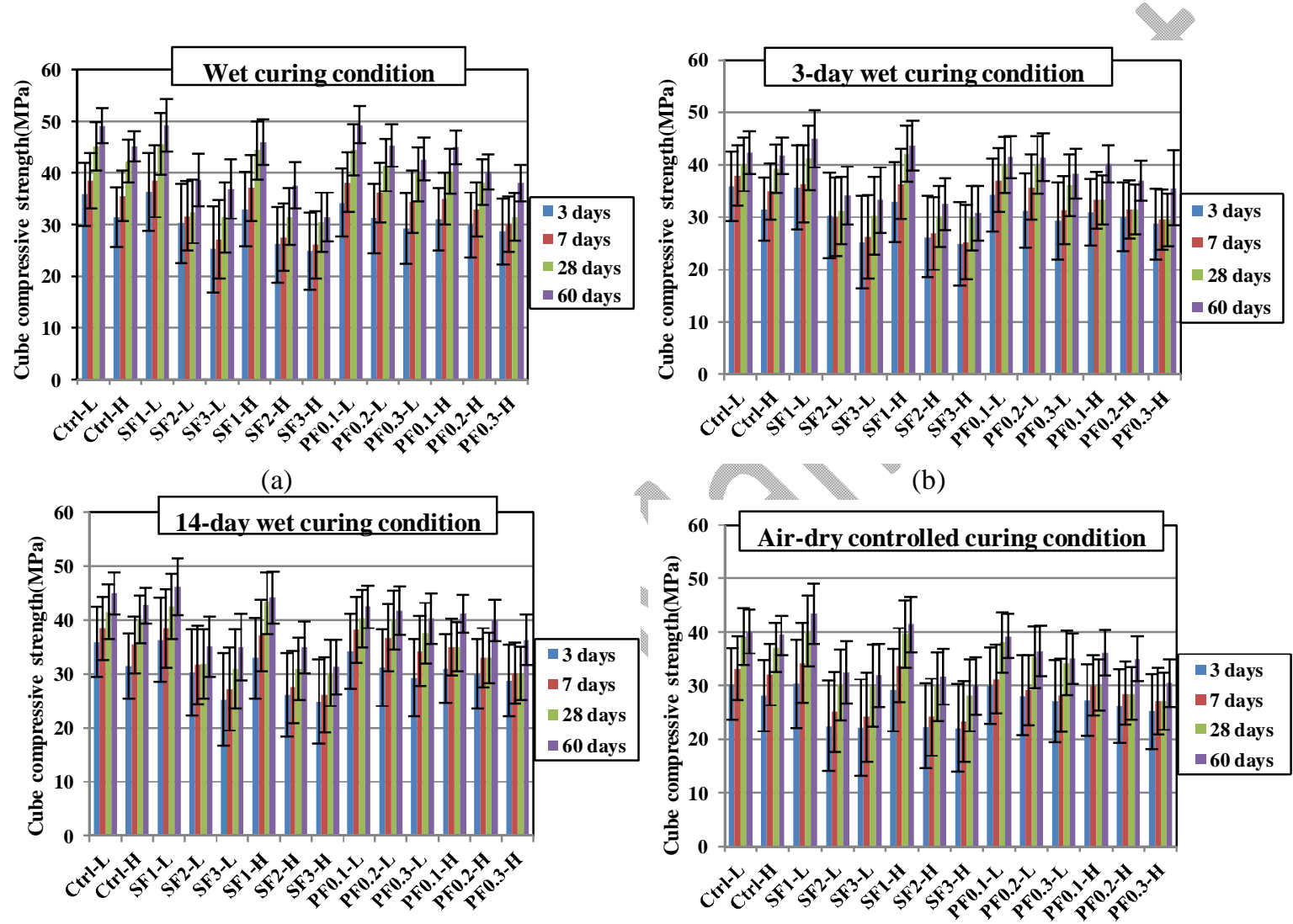

(c)

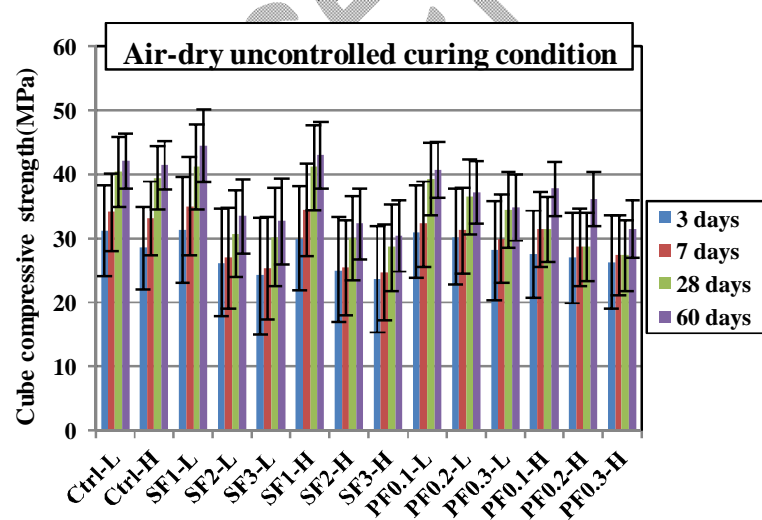

(d)

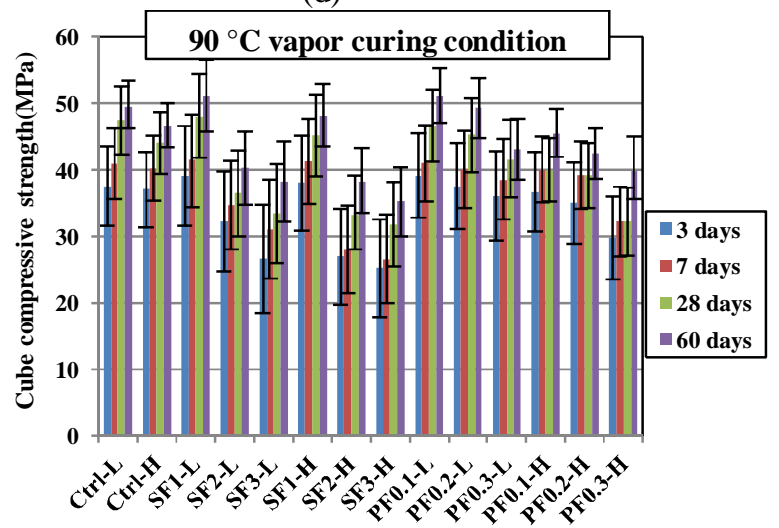

(f)

Fig. 6. Cube CS of LC mixes under: Wet curing (a); 3-day wet curing (b); 14-day wet curing (c); Air-dry controlled curing (d); Air-dry uncontrolled curing (e); $90{ }^{\circ} \mathrm{C}$ vapour curing (f) 
Table 4. Cube CS ratios of FRC mixes to control mixes

\begin{tabular}{|c|c|c|c|c|c|c|c|c|c|c|c|c|}
\hline Curing regimes & $\frac{\mathrm{SF} 1-\mathrm{L}}{\text { Crrl }-\mathrm{L}}$ & $\frac{\mathrm{SF} 2-\mathrm{L}}{\mathrm{Crrl}-\mathrm{L}}$ & $\frac{\mathrm{SF} 3-\mathrm{L}}{\mathrm{Crrl}-\mathrm{L}}$ & $\frac{\mathrm{SF} 1-\mathrm{H}}{\mathrm{Crrl}-\mathrm{H}}$ & $\frac{\mathrm{SF} 2-\mathrm{H}}{\mathrm{Orrl}-\mathrm{H}}$ & $\frac{\mathrm{SF} 3-\mathrm{H}}{\mathrm{Orrl}-\mathrm{H}}$ & $\frac{\mathrm{PF} 1-\mathrm{L}}{\mathrm{Orl}-\mathrm{L}}$ & $\frac{\mathrm{PF} 2-\mathrm{L}}{\mathrm{Orl}-\mathrm{L}}$ & $\frac{\mathrm{PF} 3-\mathrm{L}}{\mathrm{Orl}-\mathrm{L}}$ & $\frac{\mathrm{PF} 1-\mathrm{H}}{\mathrm{Orl}-\mathrm{H}}$ & $\frac{\mathrm{PF} 2-\mathrm{H}}{\mathrm{Orl}-\mathrm{H}}$ & $\frac{\mathrm{PF} 3-\mathrm{H}}{\mathrm{Orl}-\mathrm{H}}$ \\
\hline Wet & 1.01 & 0.79 & 0.71 & 1.05 & 0.8 & 0.73 & 0.99 & 0.91 & 0.87 & 0.98 & 0.92 & 0.83 \\
\hline 3-day wet & 1.01 & 0.85 & 0.78 & 1.05 & 0.79 & 0.75 & 1.04 & 0.95 & 0.86 & 0.93 & 0.88 & 0.84 \\
\hline 14-day wet & 1.02 & 0.8 & 0.74 & 1.04 & 0.8 & 0.75 & 0.96 & 0.93 & 0.88 & 0.95 & 0.91 & 0.84 \\
\hline Air-dry controlled & 1.04 & 0.77 & 0.76 & 1.05 & 0.79 & 0.76 & 0.97 & 0.91 & 0.87 & 0.9 & 0.86 & 0.8 \\
\hline Air-dry uncontrolled & 1.03 & 0.79 & 0.76 & 1.04 & 0.79 & 0.75 & 0.97 & 0.91 & 0.86 & 0.9 & 0.85 & 0.79 \\
\hline $90^{\circ} \mathrm{C}$ vapour & 1.03 & 0.82 & 0.74 & 1.03 & 0.72 & 0.68 & 1.02 & 0.98 & 0.91 & 0.92 & 0.93 & 0.8 \\
\hline
\end{tabular}

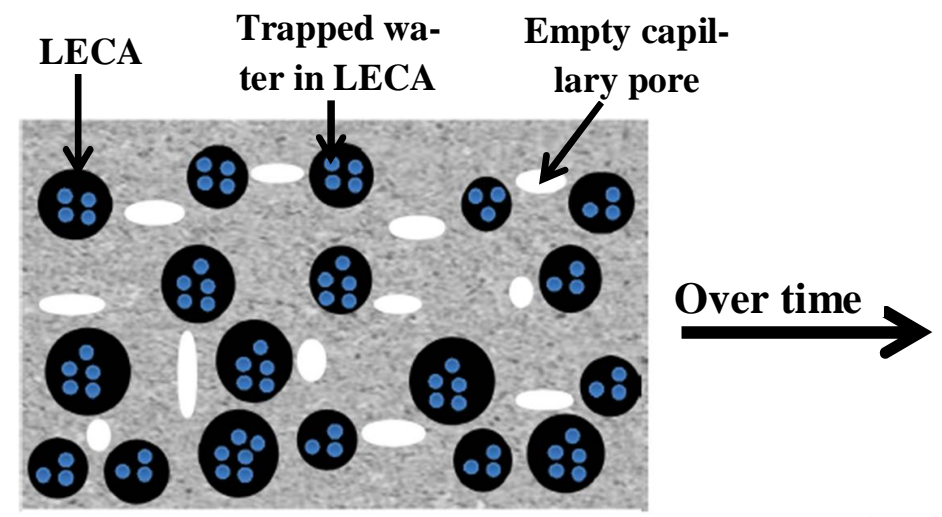

Water molecules, removed from LECA to the concrete pores

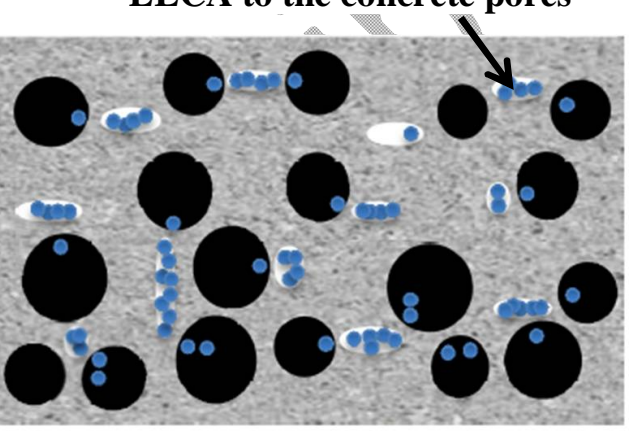

Fig. 7. Schematic of water molecules, given back to the empty capillary pores under air-dry uncontrolled curing

The fibres content has no effect on the hydration process of concrete materials. However, the CS of LC mixes decreased by adding SF except for $1 \%$ content. A study by Mohod [44] on concrete mixes with SF at $0.25-2 \%$ by volume showed that the CS of concrete increased by adding $1 \% \mathrm{SF}$. So, it can be inferred that there was a strong bond and cohesion between $1 \%$ SF and the matrix, while the results showed that the CS of concrete decreased at higher amounts of SF owing to the generation of air-voids in the concrete mixes as explained by Balaguru and Ramakishan [72]. Concerning the addition of PF, Fallah and Nematzadeh [41] showed that $0.1 \%$ incorporation of these fibres in concrete mixes slightly improved the CS, while the reverse occurred for higher volume fractions. In our study, in most cases, there was no significant difference between the results of concrete with $0.1 \% \mathrm{PF}$ and the control mixes, while the CS of LC decreased by increasing the content of PF due to clustering and pore formation, as described by Fallah and Nematzadeh [41].

In this study, the effects of low and high W/B ratios on the CS of LC were compared. Under 
$90{ }^{\circ} \mathrm{C}$ vapour and wet curing conditions, the compressive strength of concrete mixes with W/B ratio of 0.37 was on average about $9 \%$, and $9.8 \%$ more than that of the mixes with W/B ratio of 0.42, respectively. The corresponding values for the air-dry uncontrolled, air-dry controlled, 3day and 14-day wet curing conditions were about 5.1\%, 5.9\%, 5.5\% and 5.4\%, respectively. So, when concrete specimens were cured by $90{ }^{\circ} \mathrm{C}$ vapour curing and by immersion in a water tank for a long time, the difference between the results of low and high W/B ratios increased. This showed that the hydration process and chemical reactions increased more for concrete mixes with low W/B ratio (0.37) due to vapour and wet curing conditions.

FRC mixes containing LECA were efficiently cured under $90^{\circ} \mathrm{C}$ vapour curing and even the CS of concrete mixes under this curing regime was slightly higher than that under wet curing. As seen in Figs. 6(a) and (f), the cube CS of concrete mixes under $90{ }^{\circ} \mathrm{C}$ vapour curing was on average 7.2\% higher than that under wet curing. There are two explanations for this difference. First, $90{ }^{\circ} \mathrm{C}$ vapour curing leads to a faster cement hydration process at high temperatures, and this curing regime subsequently contributes to improving the silica gel properties in concrete at both early and old ages. Second, the external water in a wet curing condition can only penetrate into the concrete specimens within a few millimetres owing to its low permeability, as described by Wang et al. [57], while the external water vapour particles in the $90{ }^{\circ} \mathrm{C}$ vapour curing are much less dense than those of external liquid water as reported by Firestone [73]; thus, they can easily penetrate the concrete specimens in depth as seen in Fig. 8. In addition, 1\% SF can be seen as an optimum content in concrete mixes containing LECA to achieve an adequate CS. For instance, under $90{ }^{\circ} \mathrm{C}$ vapour curing, the CS of LC with $1 \%$ SF was on average about $3.1 \%$ higher than that of the control mixes. The corresponding value for $0.1 \%$ PF was on average about $1.8 \%$.

Comparison of data on two initial curing conditions of 3-day wet curing and $90{ }^{\circ} \mathrm{C}$ vapour cur- 
ing for 2 days showed that the $\mathrm{CS}$ values of concrete mixes under $90{ }^{\circ} \mathrm{C}$ vapour were on average about $11.8 \%, 13.8 \%, 14.18 \%$ and $15.25 \%$ more than those under 3 -day wet curing at 3, 7, 28 and 60 days, respectively. It can be inferred that the difference between the results under these curing conditions increased as the age of concrete specimens increased; therefore, the initial period of curing by $90{ }^{\circ} \mathrm{C}$ vapour for 2 days appeared to be more effective than that by water for 3 days in improving the CS of FRC and LC, particularly at older ages.

Concernig scatter of the data, the standard deviation (SD) of the control mixes under wet curing at 28 days was equal to 4.6 MPa and 4.2 MPa for the W/B ratios of 0.37 and 0.42 , respectively. Therefore, the coefficients of variation for the same mixes were $9.5 \%$ and $9.3 \%$. Similarly to the results of Mazaheripour et al. [74], the coefficient of variation for LC under wet curing condition at 28 days was equal to $9.9 \%$. This shows that the SD values of FRC mixes in the compression test increased by increasing the SF and PF content. Similar results were reported by Mazaheripour et al. [74] for FRC. This can be due to the generation of air-voids in the concrete mixes by increasing fibres. According to the results, the CS values of concrete mixes made with SF were more scattered than those of concrete mixes made with PF. The reason is that SF were bigger than PF; so, the higher amount of SF led to the generation of more and bigger air-voids in the concrete mixes. The results showed that the mid-values of SD of the concrete mixes under $90{ }^{\circ} \mathrm{C}$ vapour curing were nearly the same as those under wet curing. However, these values under $90{ }^{\circ} \mathrm{C}$ vapour curing were on average about $3 \%$ lower than those under wet curing at early ages ( 3 and 7 days), while the contrary happened at older ages (28 and 60 days). These can be due to the fact that, at early ages, the concrete specimens under $90{ }^{\circ} \mathrm{C}$ vapour curing were kept in the curing system for 2 days and the external water vapour particles in 90 ${ }^{\circ} \mathrm{C}$ vapour curing were much less dense than those of external liquid water as reported by Firestone [73]; thus, they easily penetrated the concrete specimens in depth, as seen in Fig. 8, and filled in the 
air-voids of concrete, leading to an increase in the hydration process and a decrease in SD values at early ages. But, the concrete specimens were taken out after 2 days udrer $90{ }^{\circ} \mathrm{C}$ vapour curing and they were kept under lab conditions until the date of testing. This led to the generation of some airvoids at older ages. Therefore, the mid-values of SD under $90{ }^{\circ} \mathrm{C}$ vapour curing were on average about $8.4 \%$ more than those under wet curing condition at older ages. Totally, the CS values of concrete mixes under wet and $90{ }^{\circ} \mathrm{C}$ vapour curing were less scattered than those under other types of curing, while the highest SD values were obtained for concrete mixes under air-dry uncontrolled curing. A study by Kriker et al. [75] on FRC showed that the compressive strength values under wet curing were less scattered than those under dry curing.

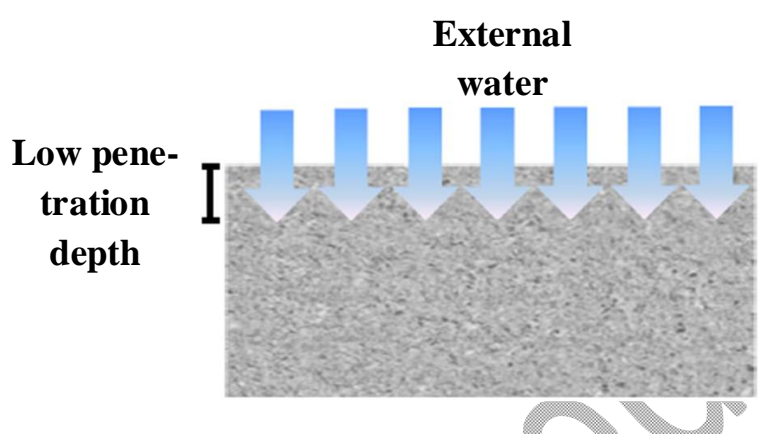

(a)

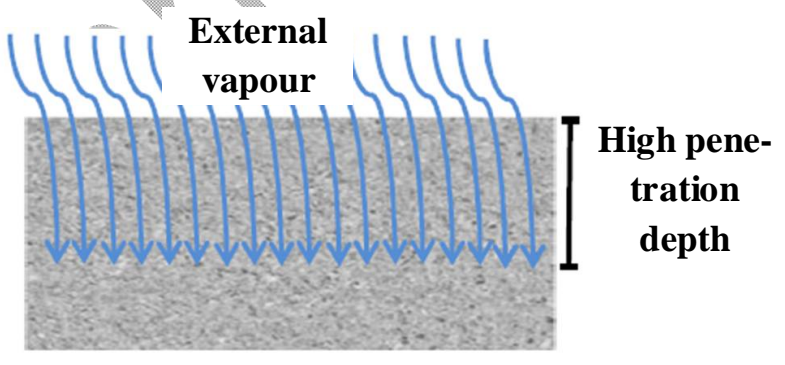

(b)

Fig. 8. Penetration depth of external liquid water and external water vapour particles into concrete specimens under wet curing (a) and $90{ }^{\circ} \mathrm{C}$ vapour curing (b)

The difference between the SD values under air-dry uncontrolled and controlled curing was negligible. It may be due to the fact that, although the free water in concrete mixes under air-dry uncontrolled curing was expected to evaporate more than that under air-dry controlled curing, the trapped water molecules in LECA were given back to the empty capillary pores to compensate the lack of free water in concrete mixes, as shown in Fig. 7. Therefore, the rate of the hydration process and the SD values under air-dry controlled and uncontrolled curing were very close. Similar results were observed between 3-day and 14-day wet curing. 


\subsection{Splitting tensile strength}

Fig. 9 shows the splitting tensile strength (STS) of LC made with various contents of PF and SF under six curing conditions at 3, 7, 28 and 60 days. The STS ratios of FRC mixes to control mixes are presented in Table 5. Similarly to the CS test, in most cases, the STS of control mixes under wet curing condition, 3-day and 14-day wet curing conditions were nearly the same, particularly at early ages (3 days and 7 days), as shown in Figs. 9 (a), (b) and (c). The STS of LC increased by increasing the SF and PF content. This can be because the addition of fibres provides bridging force across cracks, as reported by Aulia [39]. Similarly to the results of Fallah and Nematzadeh [41] for normal concrete, $0.1 \%, 0.2 \%$, and $0.3 \% \mathrm{PF}$ in LC with $\mathrm{W} / \mathrm{B}$ ratio of 0.37 under wet curing condition improved the STS up to $15.9 \%, 24.5 \%$, and $32.5 \%$, respectively. The corresponding values for $1 \%, 2 \%$, and 3\% SF were $11.5 \%, 18.7 \%$, and 30.7\%, respectively, Regarding this, Shafigh et al. [47] showed that $1 \%$ incorporation of SF improved the STS of oil palm shell LC at early and old ages. They also concluded that the addition of fibres reduced the sensitivity of LC to poor curing condition. That is why the STS of LC under air-dry uncontrolled and air-dry controlled curing conditions increased over time by the addition of fibres, as seen in Figs. 9 (d), and (e).

According to experimental observations, LC is expected to be a brittle material. However, the type of failure behaviour of FRC mixes under the STS test was ductile. On the other hand, the ductile failure behaviour of LC with SF was more than that of concrete with PF and it seems that SF bridged the cracks better and delayed the growth rate of tensile cracks more, similarly to what Hassanpour et al. [48] observed. The reason is that the tensile strength of the SF was equal to 809 $\mathrm{MPa}$, about twice that of the PF. Meanwhile, SF were longer than PF; therefore, SF better bridged the macro-cracks, as seen in Fig. 10. 


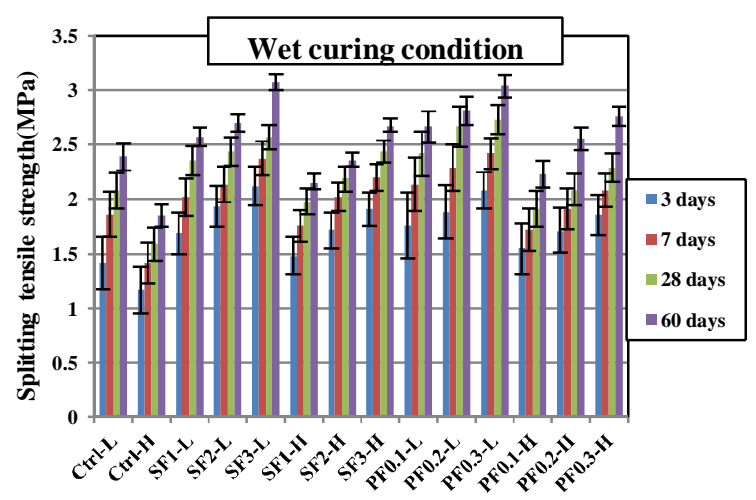

(a)

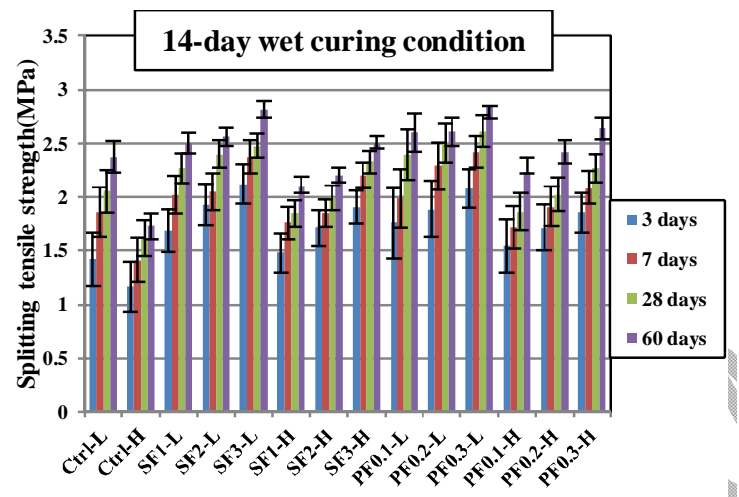

(c)

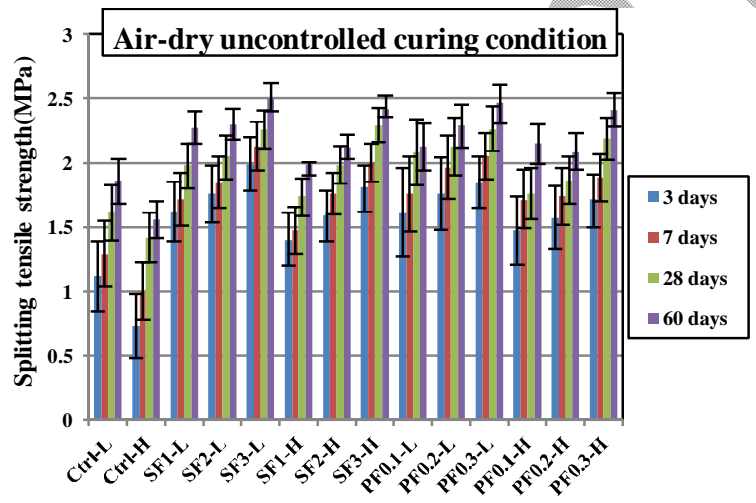

(e)

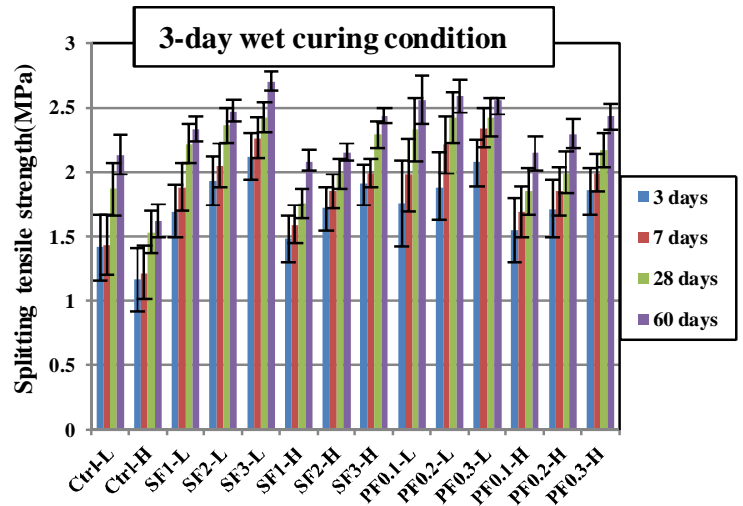

(b)

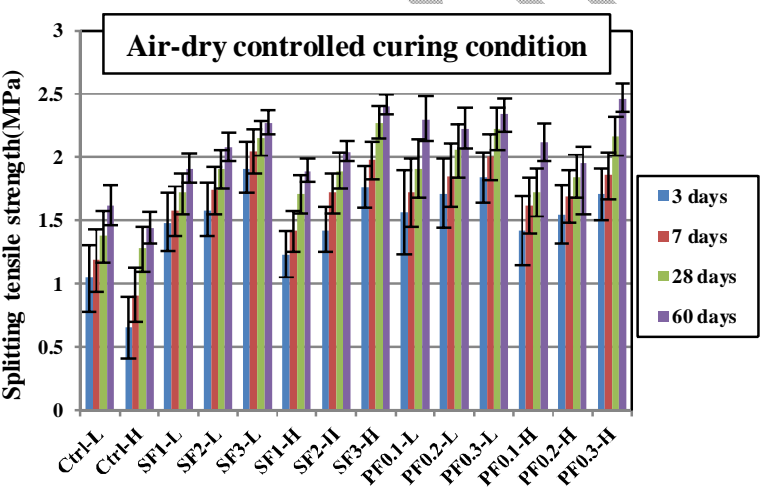

(d)

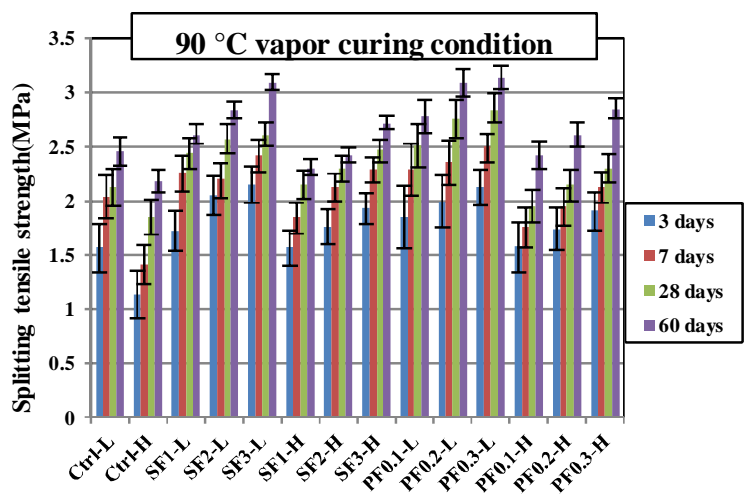

(f)

Fig. 9. STS of LC mixes under: Wet curing (a); 3-day wet curing (b); 14-day wet curing (c); Air-dry controlled curing (d); Air-dry uncontrolled curing (e); $90{ }^{\circ} \mathrm{C}$ vapour curing (f) 
Table 5. STS ratios of FRC mixes to control mixes

\begin{tabular}{|c|c|c|c|c|c|c|c|c|c|c|c|c|}
\hline Curing regimes & $\frac{\mathrm{SF} 1-\mathrm{L}}{\operatorname{Orl}-\mathrm{L}}$ & $\frac{\mathrm{SF} 2-\mathrm{L}}{\mathrm{Crrl}-\mathrm{L}}$ & $\frac{\mathrm{SF} 3-\mathrm{L}}{\mathrm{Crrl}-\mathrm{L}}$ & $\frac{\mathrm{SF} 1-\mathrm{H}}{\text { Crrl }-\mathrm{H}}$ & $\frac{\mathrm{SF} 2-\mathrm{H}}{\mathrm{Crrl}-\mathrm{H}}$ & $\frac{\mathrm{SF} 3-\mathrm{H}}{\mathrm{Grl}-\mathrm{H}}$ & $\frac{\mathrm{PF} 1-\mathrm{L}}{\mathrm{Grl}-\mathrm{L}}$ & $\frac{\mathrm{PF} 2-\mathrm{L}}{\mathrm{Arr}-\mathrm{L}}$ & $\frac{\mathrm{PF} 3-\mathrm{L}}{\mathrm{Arr}-\mathrm{L}}$ & $\frac{\mathrm{PF} 1-\mathrm{H}}{\mathrm{Orl}-\mathrm{H}}$ & $\frac{\mathrm{PF} 2-\mathrm{H}}{\mathrm{Arl}-\mathrm{H}}$ & $\frac{\mathrm{PF} 3-\mathrm{H}}{\mathrm{Crl}-\mathrm{H}}$ \\
\hline Wet & 1.12 & 1.19 & 1.3 & 1.22 & 1.38 & 1.53 & 1.16 & 1.25 & 1.33 & 1.23 & 1.37 & 1.49 \\
\hline 3-day wet & 1.19 & 1.29 & 1.39 & 1.25 & 1.39 & 1.56 & 1.26 & 1.33 & 1.37 & 1.31 & 1.42 & 1.53 \\
\hline 14-day wet & 1.1 & 1.16 & 1.27 & 1.21 & 1.31 & 1.51 & 1.14 & 1.2 & 1.29 & 1.24 & 1.36 & 1.49 \\
\hline Air-dry controlled & 1.28 & 1.4 & 1.6 & 1.46 & 1.65 & 1.96 & 1.43 & 1.5 & 1.6 & 1.6 & 1.64 & 1.91 \\
\hline Air-dry uncontrolled & 1.29 & 1.35 & 1.51 & 1.4 & 1.58 & 1.81 & 1.29 & 1.38 & 1.47 & 1.51 & 1.54 & 1.74 \\
\hline $90^{\circ} \mathrm{C}$ vapour & 1.1 & 1.18 & 1.25 & 1.2 & 1.31 & 1.43 & 1.15 & 1.24 & 1.29 & 0.85 & 1.28 & 1.4 \\
\hline
\end{tabular}

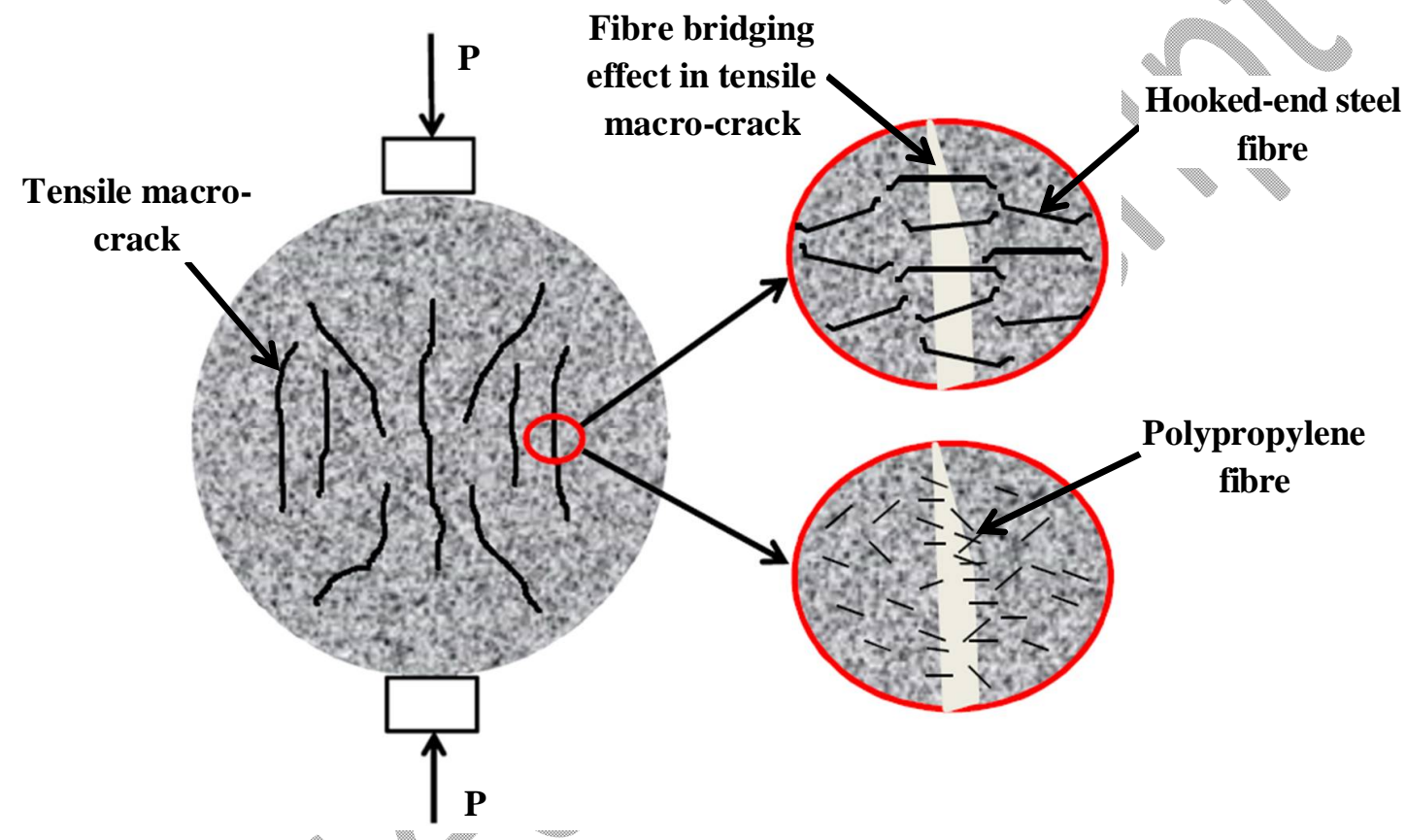

Fig. 10. Shematic representation of tensile macro-cracks in LC with SF and PF

The effects of low and high W/B ratios on the STS of LC were compared. Under air-dry uncontrolled and controlled curing conditions, the STS of concrete mixes with W/B ratio of 0.37 was on average about $9.7 \%$ and $3.1 \%$, respectively, more than that of the mixes with W/B ratio of 0.42 . The corresponding values for wet, 3 -day wet, 14 -day wet and $90{ }^{\circ} \mathrm{C}$ vapour curing conditions were about $16.1 \%, 15.5 \%, 16.3 \%$, and $16.6 \%$, respectively. So, when concrete specimens were cured by $90{ }^{\circ} \mathrm{C}$ vapour curing and by immersion in a water tank, the difference between the results of low and high W/B ratios increased. 
The results showed that the FRC mixes containing LECA were efficiently cured under $90{ }^{\circ} \mathrm{C}$ vapour curing and even the STS of concrete mixes under this curing regime was on average $4.2 \%$ higher than that under wet curing, as seen in Figs. 11(a) and (f). In addition, 3\% SF or $0.3 \%$ PF can be seen as an optimum content to obtain an adequate STS of LC. For instance, under $90{ }^{\circ} \mathrm{C}$ vapour curing, the STS of LC containing 3\% SF was on average about $33.1 \%$ higher than that of the control mixes. The corresponding value for $0.3 \% \mathrm{PF}$ was on average about $34 \%$.

The comparison of data under two initial curing conditions, 3-day wet and $90{ }^{\circ} \mathrm{C}$ vapour for 2 days, showed that the STS values of concrete mixes under $90{ }^{\circ} \mathrm{C}$ vapour curing were on average about $3.5 \%, 12.1 \%, 11.8 \%$ and $15.5 \%$ higher than those under 3 -day wet curing at 3, 7, 28 and 60 days, respectively. Similarly to CS, the initial period of curing by $90{ }^{\circ} \mathrm{C}$ vapour for 2 days appeared to be more effective than that by water for 3 days in improving the STS of FRC and LC, particularly at older ages. Another matter is that the difference between the results of STS under these two curing conditions at 3 days was only $3.5 \%$, while the corresponding difference in CS was $11.8 \%$. This can be due to the fact that the concrete mixes were not completely hardened at 3 days and they were expected to have very low tensile strength at early ages, while over time fibres content generated a suitable bond quality between aggregates and cement particles by forming a hard matrix at older ages; thus, the water vapour particles, penetrating the concrete specimens in depth at early ages (Fig. 8), effectively improved the STS of FRC by participating in the hydration process at older ages.

The SD of the control mixes under wet curing condition at 28 days was about $0.16 \mathrm{MPa}$. Therefore, the coefficient of variation for the same mixes was on average about $8.6 \%$. Similarly to the results of Mazaheripour et al. [74], the coefficient of variation for LC under wet curing condition at 28 days was equal to $6 \%$. The results showed that the STS SD values of the FRC mixes decreased as the SF and PF content increased. Similar results were obtained by Mazaheripour et al. [74] for 
FRC. It can be inferred that concrete has low tensile strength, while fibres have high tensile strength and generate a suitable bond quality between aggregates and cement particles. So, fibres prevented further dissipation of STS values. The results showed that the STS values of concrete mixes made with SF were less scattered than those of concrete mixes made with PF. The reason is that the tensile strength of SF was about twice that of PF and SF were longer than PF, as indicated in Fig. 10. Similarly to CS, the results showed that the mid-values of STS SD of the conerete mixes under $90{ }^{\circ} \mathrm{C}$ vapour curing were found to be nearly the same as under wet curing. However, these values under $90{ }^{\circ} \mathrm{C}$ vapour curing were on average about $5.7 \%$ lower than those under wet curing at early ages ( 3 and 7 days), while the corresponding values under $90^{\circ} \mathrm{C}$ vapour curing were on average about $3.4 \%$ more than those under wet curing at older ages ( 28 and 60 days). It seems that keeping concrete specimens in the $90{ }^{\circ} \mathrm{C}$ vapour curing system for 2 days efficiently prevented further scatter of the STS values at early ages. Similarly to what occurred for CS, the STS values of concrete mixes under wet and $90{ }^{\circ} \mathrm{C}$ vapour curing were less scattered than those under other types of curing, while the highest SD values were obtained for concrete mixes under air-dry uncontrolled curing. The difference between the SD values under air-dry uncontrolled and controlled curing was negligible. Similar results were observed between 3-day and 14-day wet curing.

The results of different curing conditions were used to obtain the calibration curves between the cylindrical CS and STS for LC with different contents of PF and SF, as shown in Fig. 11, where they were compared with those proposed by ACI 318 [58]. To convert the cube strength into the cylindrical strength, an appropriate conversion factor was used, as proposed by Domone [76].

For W/B ratio of 0.37 , four power equations (single-variable equations) of $f_{t}=0.0084 f_{c}^{1.52}, f_{t}=$ $0.0711 \mathrm{f}_{\mathrm{c}}^{0.98}, \mathrm{f}_{\mathrm{t}}=0.1454 \mathrm{f}_{\mathrm{c}}^{0.81}$, and $\mathrm{f}_{\mathrm{t}}=0.1542 \mathrm{f}_{\mathrm{c}}^{0.82}$ with correlation coefficients $\left(R^{2}\right)$ of $0.88,0.87$, 0.78 , and 0.88 were obtained for LC with $0 \%, 0.1 \%, 0.2 \%$, and $0.3 \% \mathrm{PF}$, respectively. The corre- 
sponding equations for W/B ratio of 0.42 were $f_{t}=0.0052 f_{c}^{1.64}, f_{t}=0.1484 f_{c}^{0.74}, f_{t}=0.15 f_{c}^{0.77}$, and $f_{t}$ $=0.1022 \mathrm{f}_{\mathrm{c}}^{0.95}$ with correlation coefficients $\left(R^{2}\right)$ of $0.76,0.75,0.79$, and 0.84 . In the previous equations, $\mathrm{f}_{\mathrm{c}}$ is the cylindrical CS and $\mathrm{f}_{\mathrm{t}}$ is the estimated tensile strength. Similar to a study by Madandoust [77] on concrete containing lightweight aggregate of lytag, the results of this study showed that the strength correlation proposed by ACI 318 [58] provided higher estimates of the tensile strength of LC and FRC containing LECA, as shown in Figs. 11(a) and (b).

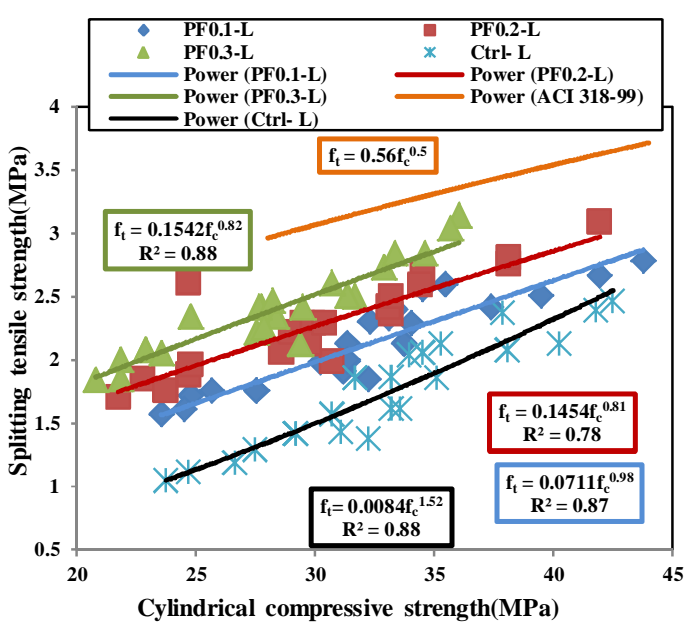

(a)

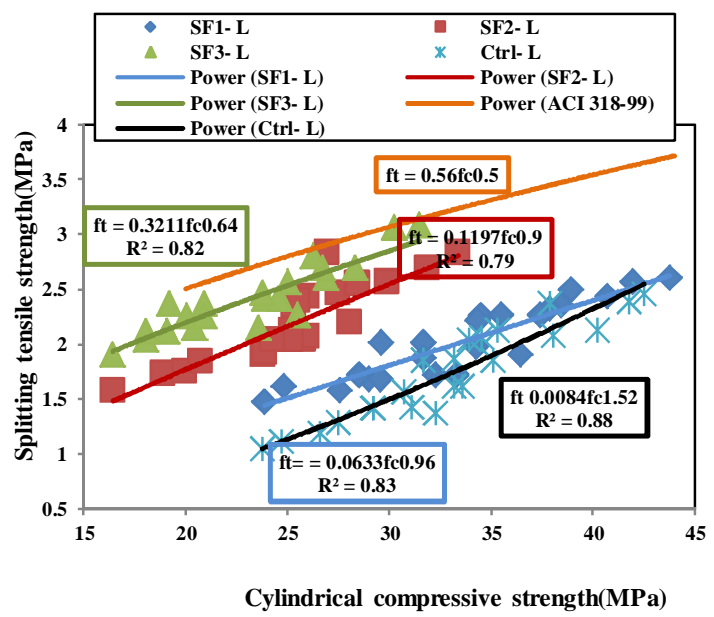

(c)

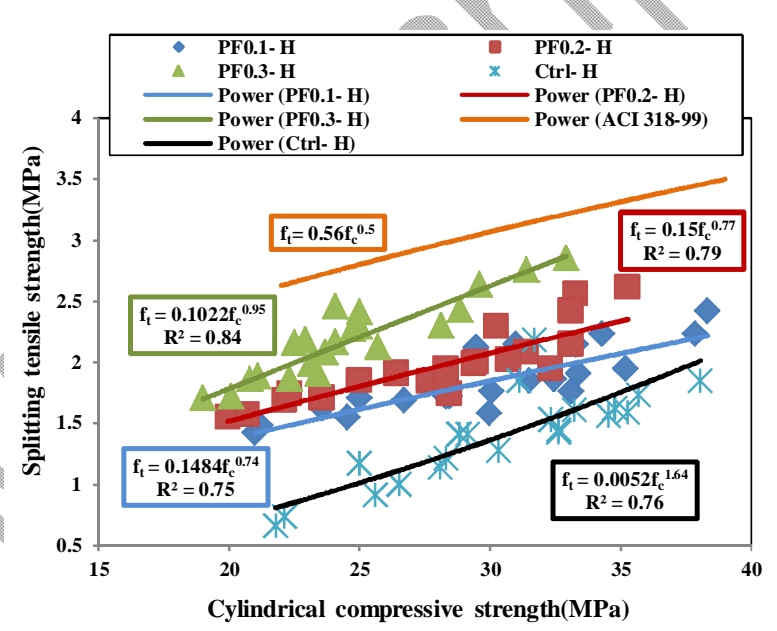

(b)

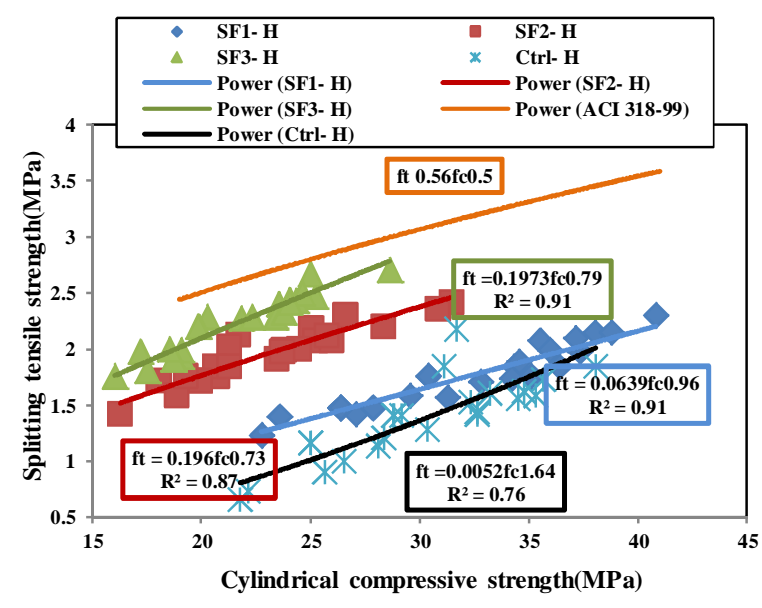

(d)

Fig. 11. Variation of STS vs. CS for LC with: PF and W/B ratio of 0.37(a); PF and W/B ratio of 0.42 (b); SF and $\mathrm{W} / \mathrm{B}$ ratio of 0.37 (c); SF and W/B ratio of 0.42 (d)

For W/B ratio of 0.37 , four power equations (single-variable equations) of $f_{t}=0.0084 f_{c}{ }^{1.52}, f_{t}$ 
$=0.0633 \mathrm{f}_{\mathrm{c}}^{0.96}, \mathrm{f}_{\mathrm{t}}=0.1197 \mathrm{f}_{\mathrm{c}}^{0.9}$, and $\mathrm{f}_{\mathrm{t}}=0.3211 \mathrm{f}_{\mathrm{c}}^{0.64}$ with correlation coefficients $\left(R^{2}\right)$ of 0.88 , $0.83,0.79$, and 0.82 were obtained for LC with $0 \%, 1 \%, 2 \%$, and $3 \%$ SF, respectively. The corresponding equations for W/B ratio of 0.42 were $\mathrm{f}_{\mathrm{t}}=0.0052 \mathrm{f}_{\mathrm{c}}^{1.64}, \mathrm{f}_{\mathrm{t}}=0.0639 \mathrm{f}_{\mathrm{c}}^{0.96}, \mathrm{f}_{\mathrm{t}}=0.196 \mathrm{f}_{\mathrm{c}}^{0.73}$, and $\mathrm{f}_{\mathrm{t}}=0.1973 \mathrm{f}_{\mathrm{c}}^{0.79}$ with correlation coefficients $\left(R^{2}\right)$ of $0.76,0.91,0.87$, and 0.91 . Similarly to what occurred for LC with PF, the strength correlation proposed by ACI 318 [58] provided higher estimates of the tensile strength of LC with SF, as seen in Figs. 11(c) and (d). It seems that the greater porosity and higher water absorption of LECA prevented more efficient chemical reactions with cement particles to form a hard matrix.

The results showed that all correlation coefficients $\left(R^{2}\right)$ were higher than 0.75 ; therefore, all equations for LC reliably predicted the tensile strength. Mean while, the estimated tensile strength values obtained using the calibration curves for LC incorporating SF were found to be closer to those using ACI 318 [58] at older ages. This can be due to the better cohesion and stronger bond between the SF and the matrix at older ages, as reported by Shafigh et al. [47]. Of the different calibration curves of FRC mixes, the strength correlation of LC made with $0.3 \%$ PF or $3 \%$ SF was closer to that of ACI $318[58]$.

\subsection{Modulus of elasticity}

As seen in Fig. 12, the effect of various contents of PF and SF on the modulus of elasticity (ME) of concrete mixes made with LECA were assessed under six curing conditions at 3, 7, 28 and 60 days. The ME ratios of FRC mixes to control mixes are presented in Table 6. The highest and lowest obtained ME values were 23.6 MPa and 14.1 MPa for LC made with $1 \%$ SF under $90{ }^{\circ} \mathrm{C}$ vapour curing condition and LC with 3\% SF under air-dry uncontrolled curing condition, respectively. So, the range of ME values, obtained for FRC mixes made with LECA, was within the values given by 
FIP [78] for LC, which ranged from 10 to $24 \mathrm{MPa}$. Similarly to CS, the ME of the control mixes under wet curing condition, 3-day and 14-day wet curing conditions were nearly the same, particularly at early ages (3 days and 7 days), as shown in Figs. 12 (a), (b) and (c).

The effects of low and high W/B ratios on the ME of LC were compared. As shown in Figs. 12 (d), and (e), under air-dry controlled and uncontrolled curing conditions, the ME values of the concrete mixes with W/B ratio of 0.37 were on average about $4 \%$ and $5.6 \%$, respectively, higher than those of the mixes with W/B ratio of 0.42 . The corresponding values for wet, 3-day wet, 14 day wet and $90{ }^{\circ} \mathrm{C}$ vapour curing conditions were about $7.1 \%, 5.7 \%, 5.8 \%$ and $8 \%$, respectively. So, when concrete specimens were cured under $90^{\circ} \mathrm{C}$ vapour curing and by immersion in a water tank, the difference between the results of low and high W/B ratios slightly increased.

The results showed that FRC mixes containing LECA were efficiently cured under $90{ }^{\circ} \mathrm{C}$ vapour curing to achieve the highest mechanical properties, where the ME of concrete mixes under this curing regime was on average $3.5 \%$ higher than that under wet curing, as seen in Figs. 12(a) and (f). Fallah and Nematzadeh [41] obtained the mechanical properties of concrete containing 0.1-0.5\% PF, where the ME of concrete decreased by adding more than $2 \%$ PF. Similarly, in this study there was no difference between the results of LC with $0.1 \% \mathrm{PF}$ and the control mix, while the ME decreased by increasing the PF content. Furthermore, LC with $1 \%$ SF can be considered as the optimum content to obtain an adequate ME of LC. For instance, under $90{ }^{\circ} \mathrm{C}$ vapour curing condition, the ME of LC with $1 \%$ SF was on average about $2.2 \%$ higher than that of the control mixes, as shown in Fig. 12 (f). 


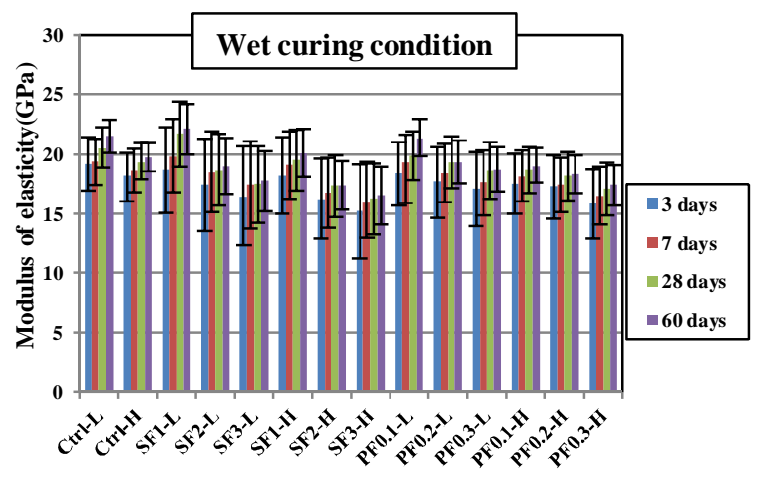

(a)

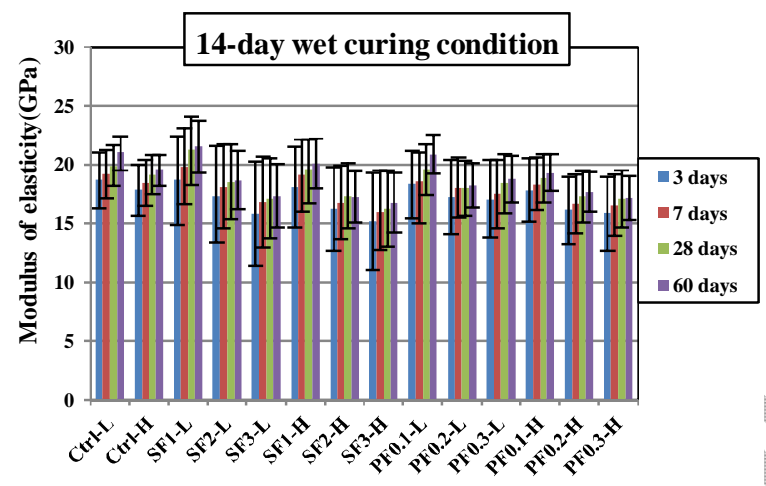

(c)

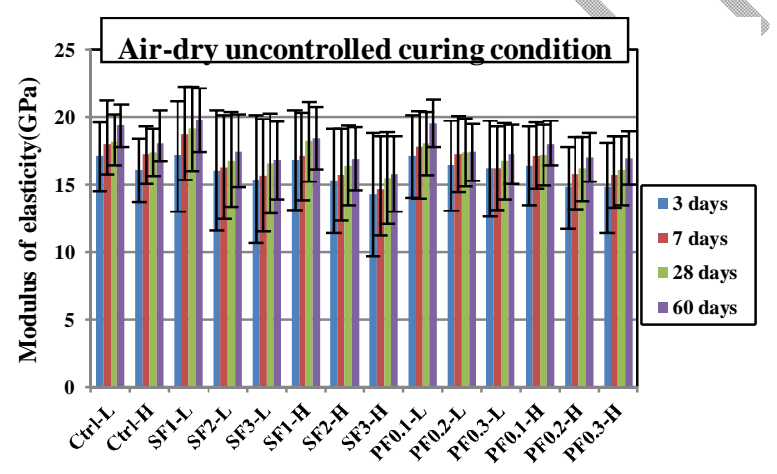

(e)

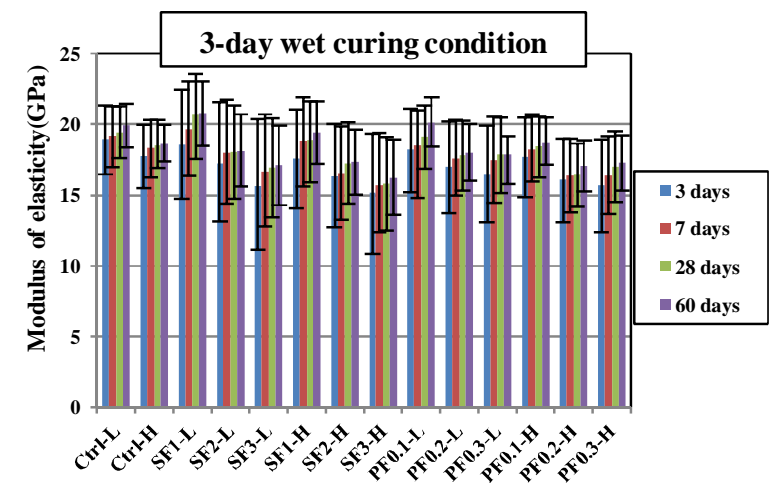

(b)

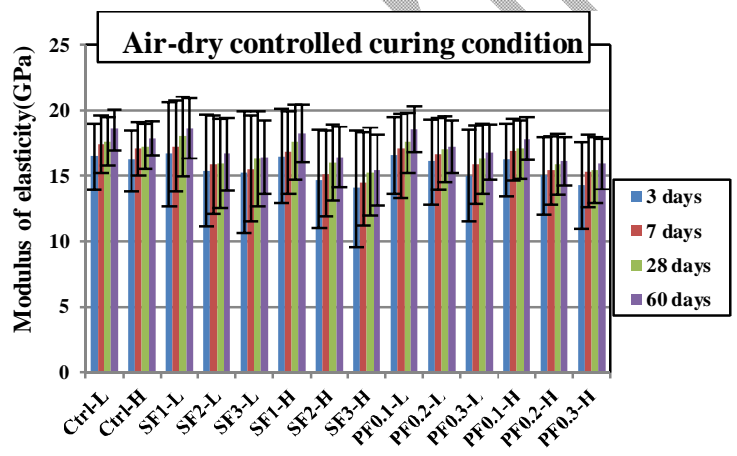

(d)

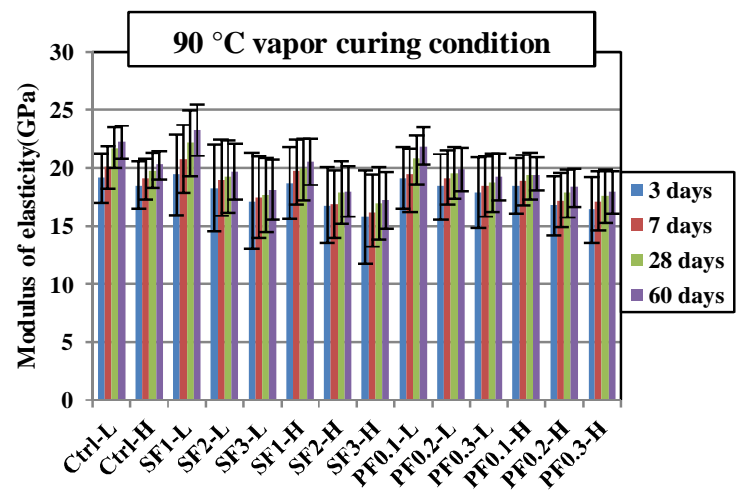

(f)

Fig. 12. ME of LC mixes under: Wet curing (a); 3-day wet curing (b); 14-day wet curing (c); Air-dry controlled curing (d); Air-dry uncontrolled curing (e); $90{ }^{\circ} \mathrm{C}$ vapour curing (f)

Table 6. ME ratios of FRC mixes to control mixes

\begin{tabular}{|c|c|c|c|c|c|c|c|c|c|c|c|c|}
\hline Curing regimes & $\frac{\mathrm{SF} 1-\mathrm{L}}{\operatorname{arl}-\mathrm{L}}$ & $\frac{\mathrm{SF} 2-\mathrm{L}}{\text { Ctrl }-\mathrm{L}}$ & $\frac{\mathrm{SF} 3-\mathrm{L}}{\mathrm{Crrl}-\mathrm{L}}$ & $\frac{\mathrm{SF} 1-\mathrm{H}}{\mathrm{Orrl}-\mathrm{H}}$ & $\frac{\mathrm{SF} 2-\mathrm{H}}{\mathrm{Crrl}-\mathrm{H}}$ & $\frac{\mathrm{SF} 3-\mathrm{H}}{\mathrm{Orl}-\mathrm{H}}$ & $\frac{\mathrm{PF} 1-\mathrm{L}}{\text { Orl-L }}$ & $\frac{\mathrm{PF} 2-\mathrm{L}}{\mathrm{Crrl}-\mathrm{L}}$ & $\frac{\mathrm{PF} 3-\mathrm{L}}{\operatorname{Crl}-\mathrm{L}}$ & $\frac{\mathrm{PF} 1-\mathrm{H}}{\mathrm{Orl}-\mathrm{H}}$ & $\frac{\mathrm{PF} 2-\mathrm{H}}{\mathrm{Grl}-\mathrm{H}}$ & $\frac{\mathrm{PF} 3-\mathrm{H}}{\mathrm{Orl}-\mathrm{H}}$ \\
\hline Wet & 1.02 & 0.91 & 0.86 & 1.01 & 0.89 & 0.84 & 0.98 & 0.93 & 0.89 & 0.97 & 0.94 & 0.88 \\
\hline 3-day wet & 1.03 & 0.92 & 0.86 & 1.02 & 0.92 & 0.86 & 1.04 & 0.91 & 0.9 & 1 & 0.9 & 0.9 \\
\hline 14-day wet & 1.03 & 0.92 & 0.85 & 1.02 & 0.9 & 0.86 & 0.98 & 0.91 & 0.91 & 0.99 & 0.9 & 0.89 \\
\hline Air-dry controlled & 1 & 0.91 & 0.91 & 1.01 & 0.91 & 0.87 & 0.99 & 0.96 & 0.91 & 1 & 0.91 & 0.89 \\
\hline Air-dry uncontrolled & 1.02 & 0.91 & 0.88 & 1.03 & 0.93 & 0.88 & 1 & 0.94 & 0.91 & 0.99 & 93 & 0.92 \\
\hline $90{ }^{\circ} \mathrm{C}$ vapour & 1.03 & 0.92 & 0.84 & 1.02 & 0.89 & 0.85 & 0.97 & 0.92 & 0.89 & 0.98 & 0.9 & 0.88 \\
\hline
\end{tabular}


Similarly to what occurred for CS and STS, in most cases the ME values of concrete mixes with $0.37 \mathrm{~W} / \mathrm{B}$ ratio were slightly more scattered than those with $0.42 \mathrm{~W} / \mathrm{B}$ ratio, due to the generation of more air-voids in the concrete mixes with lower W/B ratio. For instance, the SD of the control mixes under wet curing at 28 days was on average about $1.7 \mathrm{GPa}$ and $1.5 \mathrm{GPa}$ for the W/B ratios of 0.37 and 0.42, respectively, as shown in Fig. 12 (a). However, there was no significant difference between the $\mathrm{SD}$ of concrete mixes with low and high $\mathrm{W} / \mathrm{B}$ ratios. The reason is that the trapped water molecules in LECA were given back to the empty capillary pores to compensate the lack of free water in concrete mixes, as shown in Fig. 7. Meanwhile, the SD values of FRC mixes in the ME test increased as the SF and PF content increased. Generally, the CS values of concrete mixes under wet and $90{ }^{\circ} \mathrm{C}$ vapour curing were less scattered than those under other types of curing conditions, while the highest SD values were obtained for concrete mixes under air-dry uncontrolled curing.

The relationships between the cylindrical CS and ME for LC with various contents of PF and SF are shown in Fig. 13 and compared with the equation proposed by ACI 318 [58].

For W/B ratio of 0.37, four power equations (single-variable equations) of $\mathrm{E}_{\mathrm{c}}=3.9508 \mathrm{f}_{\mathrm{c}}^{0.46}, \mathrm{E}_{\mathrm{c}}=$ $4.6352 \mathrm{f}_{\mathrm{c}}^{0.41}, \mathrm{E}_{\mathrm{c}}=7.1931 \mathrm{f}_{\mathrm{c}}^{0.27}$, and $\mathrm{E}_{\mathrm{c}}=5.6774 \mathrm{f}_{\mathrm{c}}^{0.34}$ with correlation coefficients $\left(R^{2}\right)$ of $0.82,0.88$, 0.72 , and 0.79 were obtained for LC with $0 \%, 0.1 \%, 0.2 \%$, and $0.3 \% \mathrm{PF}$, respectively, as indicated in Fig. 13(a). According to Figs. 13(b), the corresponding equations for W/B ratio of 0.42 were $E_{c}=$ $6.6763 \mathrm{f}_{\mathrm{c}}^{03}, \mathrm{E}_{\mathrm{c}}=7.2633 \mathrm{f}_{\mathrm{c}}^{0.27}, \mathrm{E}_{\mathrm{c}}=5.9683 \mathrm{f}_{\mathrm{c}}^{0.31}$, and $\mathrm{E}_{\mathrm{c}}=4.9706 \mathrm{f}_{\mathrm{c}}^{0.37}$ with correlation coefficients $\left(R^{2}\right)$ of $0.7,0.79,0.71$, and 0.81 , where $\mathrm{f}_{\mathrm{c}}$ is the cylindrical CS and $\mathrm{E}_{\mathrm{c}}$ is the estimated ME. The results of this study showed that the correlation curves proposed by ACI 318 [58] provided higher estimates of the ME of LC and FRC with LECA. Similarly, the correlation curves of LC proposed by Tomosawa and Noguchi [79] underestimated the ME of normal concrete. Of the different calibration curves, 
the one of the LC control mix was closer to that of ACI 318 [58].

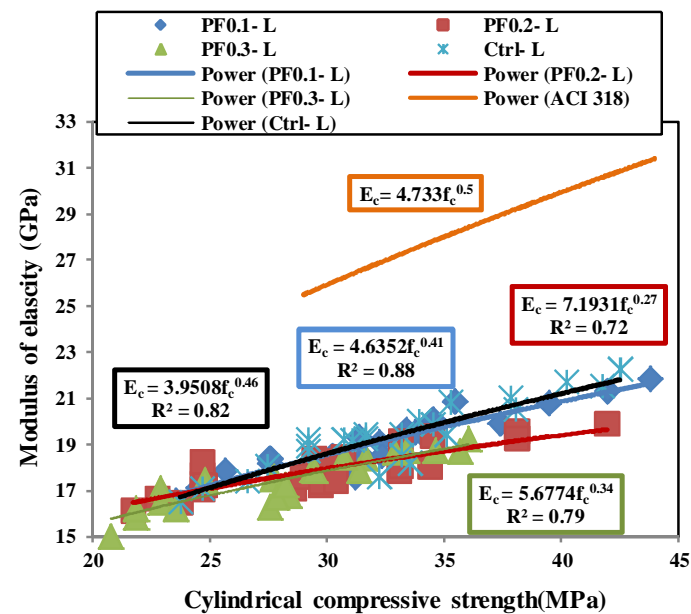

(a)

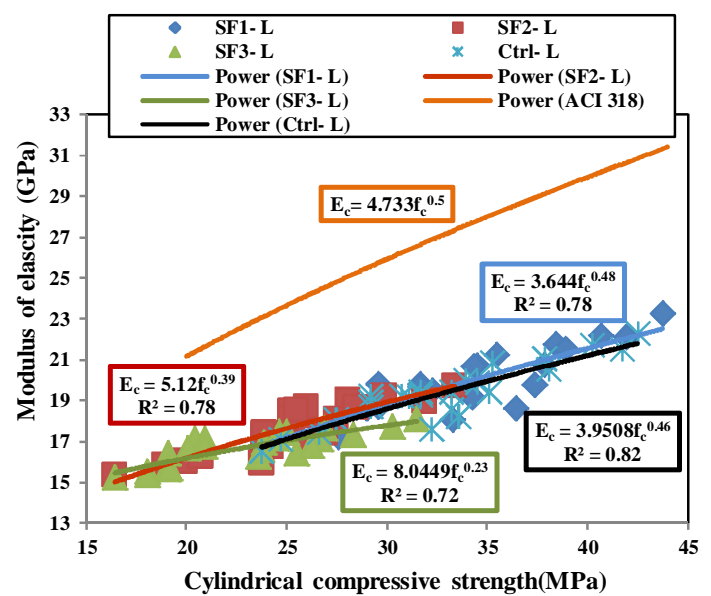

(c)

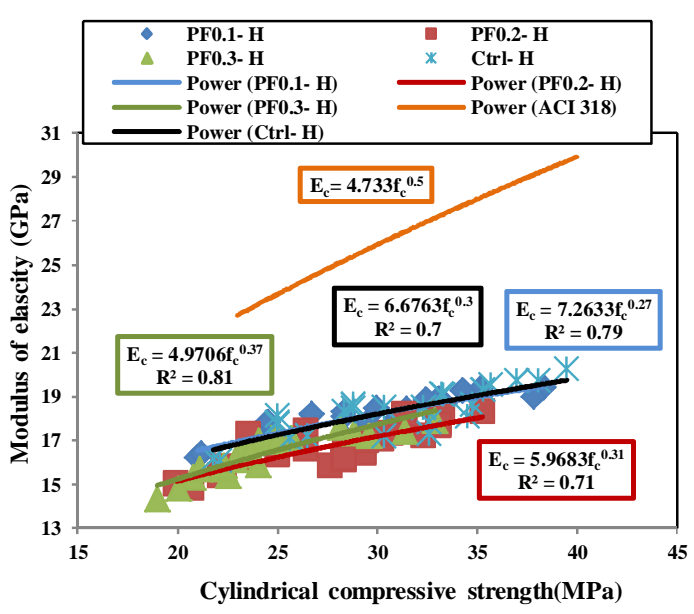

(b)

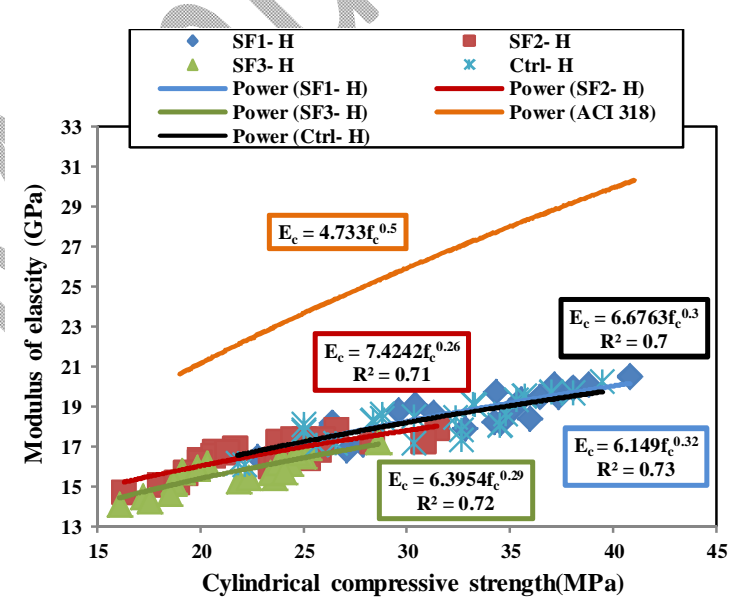

(d)

Fig. 13. Variation of ME vs. CS for LC with: PF and W/B ratio of $0.37(a)$; PF and W/B ratio of 0.42 (b); SF and W/B ratio of 0.37 (c); SF and W/B ratio of 0.42 (d)

Concerning the addition of SF, for W/B ratio of 0.37 , four power equations (single-variable equations) of $\mathrm{E}_{\mathrm{c}}=3.9508 \mathrm{f}_{\mathrm{c}}^{0.46}, \mathrm{E}_{\mathrm{c}}=3.644 \mathrm{f}_{\mathrm{c}}^{0.48}, \mathrm{E}_{\mathrm{c}}=5.12 \mathrm{f}_{\mathrm{c}}^{0.39}$, and $\mathrm{E}_{\mathrm{c}}=8.0449 \mathrm{f}_{\mathrm{c}}^{0.23}$ with correlation coefficients $\left(R^{2}\right)$ of $0.82,0.78,0.78$, and 0.72 were obtained for LC with $0 \%, 1 \%, 2 \%$, and $3 \% \mathrm{SF}$, respectively. The corresponding equations for W/B ratio of 0.42 were $\mathrm{E}_{\mathrm{c}}=6.6763 \mathrm{f}_{\mathrm{c}}^{0.3}, \mathrm{E}_{\mathrm{c}}$ $=6.149 \mathrm{f}_{\mathrm{c}}^{0.32}, \mathrm{E}_{\mathrm{c}}=7.4242 \mathrm{f}_{\mathrm{c}}^{0.26}$, and $\mathrm{E}_{\mathrm{c}}=6.3954 \mathrm{f}_{\mathrm{c}}^{0.29}$ with correlation coefficients $\left(R^{2}\right)$ of 0.7 , 0.73, 0.71, and 0.72. Similarly to LC with PF, the correlation curve proposed by ACI 318 [58] 
overestimated the ME of LC with SF, as seen in Figs. 13(c) and (d). Of the different calibration curves of FRC mixes, the one of LC made with 1\% SF was closer to that of ACI 318 [58]. According to Fig. 13, all correlation coefficients $\left(R^{2}\right)$ were higher than 0.7 ; therefore, all equations for LC mixes can reliably estimate the ME.

\section{Conclusions}

This paper investigated the effect of SF and PF at various contents on the mechanical properties of concrete with LECA under six curing conditions at early and old ages. According to the experimental results, the following main conclusions can be drawn:

- The CS of the LC control mixes under wet, 3-day and 14-day wet curing were nearly the same, particularly at early ages (3 days and 7 days), while these values for W/B ratios of 0.37 and 0.42 under wet curing were on average about $11 \%$ and $17.2 \%$, respectively, higher than those under 3-day and 14-day wet curing at 28 and 60 days. In addition, the CS of the LC control mixes under 3-day wet curing were higher than those under air-dry uncontrolled curing, particularly at early ages, while there was no significant difference between the results under these curing regimes at older ages;

- A comparison of the various curing conditions showed that, under $90{ }^{\circ} \mathrm{C}$ vapour and wet curing, the hydration process and chemical reactions increased more for concrete mixes with the low W/B ratio (0.37), leading to an increase in the difference between the results of low and high $\mathrm{W} / \mathrm{B}$ ratios;

- The $90{ }^{\circ} \mathrm{C}$ vapour curing can be considered as the best curing condition for FRC mixes with LECA to achieve the highest CS, where the cube CS of concrete mixes under $90{ }^{\circ} \mathrm{C}$ vapour curing was on average $7.2 \%$ higher than that of the mixes under wet curing; 
- $1 \% \mathrm{SF}$ can be seen as the optimum content in concrete mixes with LECA to achieve the highest CS and ME. Meanwhile, 3\% SF or 0.3\% PF can be considered the optimum content to obtain an adequate STS of LC;

- The ductile failing behaviour of LC with SF was more evident than that of concrete with PF and it seems that SF can better bridge the cracks and further delay the growth rate of tensile cracks;

- Similarly to the CS test, the FRC mixes containing LECA were efficiently cured under $90{ }^{\circ} \mathrm{C}$ vapour curing to achieve the highest STS and ME;

- The comparison of data under two initial curing conditions of 3-day wet curing and 90 ${ }^{\circ} \mathrm{C}$ vapour curing for 2 days showed that the difference between the results of these curing conditions increased by increasing the age of concrete specimens and the initial period of curing by $90{ }^{\circ} \mathrm{C}$ vapour for 2 days was more effective than that by water for 3 days in improving the mechanical properties of FRC and LC, particularly at older ages;

- For CS, the SD of FRC mixes increased as the SF and PF content increased, contrarily to STS. Meanwhile, the CS values of concrete mixes made with SF were more scattered than those of concrete mixes made with PF. However, the STS values of concrete mixes made with SF were less scattered than those of concrete mixes made with PF;

- The CS values of concrete mixes under wet and $90{ }^{\circ} \mathrm{C}$ vapour curing were less scattered than those under other types of curing, while the highest SD values were obtained for concrete mixes under air-dry uncontrolled curing. Meanwhile, the SD values under air-dry controlled and uncontrolled curing were very close to each other, similarly to what occurred for STS;

- The mid-values of CS SD of the concrete mixes under $90{ }^{\circ} \mathrm{C}$ vapour curing were 
found to be nearly the same under wet curing, similarly to what occurred for STS. However, these values under $90{ }^{\circ} \mathrm{C}$ vapour curing for CS and STS were on average about $3 \%$ and $5.7 \%$, respectively, lower than those under wet curing at early ages (3 and 7 days), while the corresponding values under $90{ }^{\circ} \mathrm{C}$ vapour curing were on average about $8.4 \%$ and $3.4 \%$ more than those under wet curing at older ages (28 and 60 days);

- In most cases, the mechanical strengths of concrete mixes with $0.37 \mathrm{~W} / \mathrm{B}$ ratio were slightly more scattered than those with $0.42 \mathrm{~W} / \mathrm{B}$ ratio. However, the incorporation of LECA prevented further scatter of mechanical strengths of concrete mixes with low $\mathrm{W} / \mathrm{B}$ ratio in the CS, STS and ME tests;

- The one-variable equations reliably estimated the STS and ME of FRC with LECA. In addition, the correlation curves proposed by ACI 318 overestimated the STS and ME of LC and FRC with LECA;

- By increasing the age of concrete mixes under different curing conditions, the estimated STS values obtained using the calibration curves for LC incorporating SF were found to be closer to those using ACI 318 and the bridging effect of SF appeared to be more effective than that of $\mathrm{PF}$ in preventing macro-cracks propagation, particularly at older ages;

- Of the different calibration curves to estimate the STS of FRC mixes, the one of LC made with $0.3 \% \mathrm{PF}$ or $3 \% \mathrm{SF}$ was closer to that of ACI 318. Concerning the estimated ME, the correlation curve of control mix and LC made with $1 \%$ SF was closer to that of ACI 318.

\section{References}

1. C. Meyer, The greening of the concrete industry, Cement and Concrete Composites, 31(8) (2009) 601-605.

2. M. Saberian, J. Li, B.T. Nguyen, S. Setunge, Estimating the resilient modulus of crushed recycled pavement materials containing crumb rubber using Clegg impact value, Resources, Conservation and Recycling, 141 (2019) 301-307. 
3. M. Kazemi, R. Madandoust, J. de Brito, Compressive strength assessment of recycled aggregate concrete using Schmidt rebound hammer and core testing, Construction and Building Materials, 224 (2019) 630-638.

4. J.A. Bogas, J. de Brito, J.M. Figueiredo, Mechanical characterization of concrete produced with recycled lightweight expanded clay aggregate concrete, Journal of Cleaner Production, 89 (2015) 187-195.

5. M. Saberian, J. Li, D. Cameron, Effect of crushed glass on behavior of crushed recycled pavement materials together with crumb rubber for making a clean green base and subbase, Journal of Materials in Civil Engineering , 31(7) (2019) 1-7.

6. J.A. Bogas, J. Brito, J. Cabaço, Long-term behaviour of concrete produced with recycled lightweight expanded clay aggregate concrete, Construction and Building Materials, 65 (2014) 470-479.

7. M. Medine, H. Trouzine, J.B. De Aguiar, A. Asroun, Durability of five years aged lightweight concretes containing rubber aggregates, Periodica Polytechnica Civil Engineering, 62(2) (2018) 386-397.

8. S. Iqbal, A. Ahsan, K. Holschemacher, Y. Ribakov, T.A. Bier, Effect of fly ash on properties of selfcompacting high strength lightweight concrete, Periodica Polytechnica Civil Engineering, 61 (2017) 81.

9. H. AzariJafari, A. Tajadini, M. Rahimi, J. Berenjian, Reducing variations in the test results of self-consolidating lightweight concrete by incorporating pozzolanic materials, Construction and Building Materials, 166 (2018) 889-897.

10. M. Maghfouri, P. Shafigh, Z. Binti Ibrahim, V. Alimohammadi, Quality control of lightweight aggregate concrete based on initial and final water absorption tests, IOP Conference Series, Materials Science and Engineering, 210(1) (2017) 1-14.

11. T.A. Holm, T.W. Bremner, State-of-the-art report on high-strength, high durability structural low-density concrete for applications in severe marine environments. Us Army Corps of Engineers, Washington, USA. Structural Laboratory, ERDC/SL TR-00-3, (2000).

12. S. Chandra, L. Berntsson, Lightweight aggregate concrete, science, technology and applications, Noyes publications -William Andrew Publishing, USA, (2003).

13. J.B. Newman, Properties of structural lightweight aggregate concrete, In: Clarke, J.L. (Ed.), Structural Lightweight Aggregate Concrete. Chapman \& Hall, London, UK, (1993) 19-44.

14. J.A. Bogas, Characterization of structural lightweight expanded clay aggregate concrete, $\mathrm{PhD}$ thesis in Civil Engineering. Technical University of Lisbon, Instituto Superior Tecnico, Lisbon, Portugal (in Portuguese), (2011).

15. Netweber. LECA [Online]. Available from: 〈http://www.netweber.co.uk/ fileadmin/user_upload/Literature/LECA__LWA_Brochure_LR-V1.pdf) (Accessed 12 July 2015).

16. P. Shafigh, L.J. Chai, H.B. Mahmud, M.A. Nomeli, A comparison study of the fresh and hardened properties of normal weight and lightweight aggregate concretes, Journal of building Engineering, 15 (2018) 252-260.

17. L. Evangelista, J. de Brito, Mechanical behaviour of concrete made with fine recycled concrete aggregates, Cement and Concrete Composites, 29(5) (2007) 397-401.

18. S.T. Yildirim, C. Meyer, S. Herfellner, Effects of internal curing on the strength, drying shrinkage and freeze-thaw resistance of concrete containing recycled concrete aggregates, Construction and Building Materials, 91 (2015) 288-296. 
19. L. Ferreira, J. de Brito, M. Barra, Influence of the pre-saturation of recycled coarse concrete aggregates on the fresh and hardened properties of concrete, Magazine of Concrete Research, 63(8) (2011) 617-627.

20. N. Saikia, J. de Brito, Use of plastic waste as aggregate in cement mortar and concrete preparation: a review, Construction and Building Materials, 34 (2012) 385-401.

21. A. Hassan, N. Ismail, A.H. Mourad, Y. Rashid, M. Laghari, Preparation and characterization of expanded clay-paraffin wax-geo-polymer composite material, Materials, 11(11) (2018) 1-16.

22. P. Tataranni, G.M. Besemer, V. Bortolotti, C. Sangiorgi, Preliminary research on the physical and mechanical properties of alternative lightweight aggregates produced by alkali-activation of waste powders, Materials, 11(7) (2018) 1-17.

23. B. Hubertova, R. Hela, Durability of light weight expanded clay aggregate concrete, Procedia Engineering, 65 (2013) 2-6.

24. A. Hassan, A.-H.I. Mourad, Y. Rashid, N. Ismail, M.S. Laghari, Thermal and structural performance of geopolymer concrete containing phase change material encapsulated in expanded clay, Energy and Buildings, 191(15) (2019) 72-81.

25. S. Mindess, J.F. Young, D. Darwin, Concrete, Second edition, Prentice Hall, Upper Saddle River, NJ, (2002).

26. G. Espinoza-Hijazin, M. Lopez, Extending internal curing to concrete mixtures with W/C higher than 0.42 , Construction and Building Materials, 25 (2011) 1236-1242.

27. R. Madandoust, M. Kazemi, S.Y. Moghadam, Analytical study on tensile strength of concrete, Romanian Journal of Materials, 47(2) (2017) 204-209.

28. R. Madandoust, Z.F.Z. Bazkiyaei, M. Kazemi, Factor influencing point load tests on concrete. Asian Journal of Civil Engineering, 19(8) (2018) 937-947.

29. S.S. Shoabjareh, F. Soltani, A. Heidaripanah, S. Jahandari, M. Abedi, Laboratory study of the effect of temperature on strength and stress-strain curve of limestabilized soil, Bulletin of Environment, Pharmacology and Life Sciences, 4 (7) (2015).

30. V. Toufigh, M. Jafarian Abyaneh, K. Jafari, Study of behavior of concrete under axial and triaxial compression, ACI Mater. J. 114 (04) (2017) 619-629.

31. R. Madandoust, M. Kazemi, Numerical analysis of break-off test method on concrete, Construction and Building Materials, 151 (2017) 487-493.

32. R. Vali, E.M. Khotbehsara, M. Saberian, J. Li, M. Mehrinejad, S. Jahandari, A three-dimensional numerical comparison of bearing capacity and settlement of tapered and under-reamed piles, International Journal of Geotechnical Engineering, 13(3) (2019) 236-248.

33. A. Sadrmomtazi, B. Tahmouresi, A. Saradar, Effects of silica fume on mechanical strength and microstructure of basalt fiber reinforced cementitious composites (BFRCC), Construction and Building Materials, 162 (2018) 321-333.

34. A. Saradar, B. Tahmouresi, E. Mohseni, A. Shadmani, Restrained shrinkage cracking of fiber-reinforced highstrength concrete, Fibers, 6 (1) (2018) 1-13.

35. S. Yousefi Moghadam, R. Madandoust, M.M. Ranjbar, M. Kazemi, Analytical study on the behavior of cor- 
rosion damaged reinforced concrete beams strengthen with FRP, Romanian Journal of Materials, 47(4) (2017), 514 - 521.

36. M. Grzybowski, S.P. Shah, Shrinkage cracking of fiber reinforced concrete, ACI Materials Journal, 87(2) (1990) 138-148.

37. K. Kurono, Y. Sato, T. Otani, H. Okada, H. Nagano, Improvement of the resistance to concrete spalling by using a nylon fiber, Report of the faculty of engineering, Oita university, 54 (2007) 13-18.

38. R.V. Balendran, F.P. Zhou, A. Nadeem, A.Y.T. Leung, Influence of steel fibres on strength and ductility of normal and lightweight high strength concrete, Building and Environment, 37(12) (2002) 1361-1367.

39. T.B. Aulia, Effects of polypropylene fibers on the properties of high-strength coneretes, Lacer: Institutes for Massivbau and Baustoffechnologi, University Leipzig, (2002) 43-59.

40. N. Banthia, R. Gupta, Influence of polypropylene fiber geometry on plastic shrinkage cracking in concrete, Cement and Concrete Research, 36(7) (2006) 1263-1267.

41. S. Fallah, M. Nematzadeh, Mechanical properties and durability of high strength concrete containing macropolymeric and polypropylene fibers with nano-silica and silica fume. Construction and Building Materials, 132 (2017) 170-187.

42. H. Zhang, L. Wang, K. Zheng, T.J. Bakura, P.G. Totakhil, Research on compressive impact dynamic behavior and constitutive model of polypropylene fiber reinforced concrete, Construction and Building Materials, 187 (2018) 584-595.

43. H. Yan, W. Sun, H. Chen, The effect of silica fume and steel fiber on the dynamic mechanical performance of high-strength concrete, Cement and Concrete Research, 29(3) (1999) 423-426.

44. M.V. Mohod, Performance of steel fiber reinforced concrete, International Journal of Engineering Science, 1(2) (2012) 1-4.

45. V. Afroughsabet, T. Ozbakkaloglu, Mechanical and durability properties of high-strength concrete containing steel and polypropylene fibers, Construction and Building Materials, 94 (2015) 73-82.

46. A. Bhutta, P.H.R. Borges, C. Zanotti, M. Farooq, N. Banthia, Flexural behavior of geopolymer composites reinforced with steel and polypropylene macro fibers, Cement and Concrete Composites, 80 (2017) 31-40.

47. P. Shafigh, H. Mahmud, M.Z. Jumaat, Effect of steel fiber on the mechanical properties of oil palm shell lightweight concrete, Materials \& Design, 32(7) (2011) 3926-3932.

48. M. Hassanpour, P. Shafigh, H.B. Mahmud, Mechanical Properties of structural lightweight aggregate concrete containing low volume steel fiber, Arabian Journal for Science and Engineering, 39(5) (2014) 3579-3590.

49. M.Zohrabi, A. Zohrabi, A.G. Chermahini, Investigation of the mechanical properties of lightweight concrete containing LECA with metakaoline pozzolan using polypropylene and steel fibers, Journal of Applied Environmental and Biological Sciences, 5(12S) (2015) 11-15.

50. S. Jahandari, M. Saberian, Z. Tao, S. Faridfazel Mojtahedi, J. Li, M. Ghasemi, S.S. Rezvani, W. Li, Effects of saturation degrees, freezing thawing, and curing on geotechnical properties of lime and lime-cement concretes, Cold Regions Science and Technology, 160 (2019) 242-251.

51. S. Jahandari, M. Saberian, F. Zivari, J. Li, M. Ghasemi, R. Vali, Experimental study of the effects of curing 
time on geotechnical properties of stabilized clay with lime and geogrid, International Journal of Geotechnical Engineering, 13(2) (2019) 1-12.

52. X. Fu, D.D.L. Chung, Effect of curing age on the self-monitoring behavior of carbon fiber reinforced mortar, Cement and Concrete Research, 27(9) (1997) 1313-1318.

53. M. Gholhaki, A. Kheyroddin, M. Hajforoush, M. Kazemi, An investigation on the fresh and hardened properties of self-compacting concrete incorporating magnetic water with various pozzolanic materials, Construction and Building Materials, 158 (2018) 173-180.

54. H. AzariJafari, A. Kazemian, M. Rahimi, A. Yahia, Effects of pre-soaked super absorbent polymers on fresh and hardened properties of self-consolidating lightweight concrete, Construction and Building Materials, 113 (2016) 215-220.

55. H. AzariJafari, M.J.T. Amiri, A. Ashrafian, H. Rasekh, M.J. Barforooshi, J. Berenjian, Ternary blended cement: an eco-friendly alternative to improve resistivity of high-performance self-consolidating concrete against elevated temperature, Journal of Cleaner Production, 223 (2019) 575-586.

56. T.A. Soylev, T. Ozturan, Durability, physical and mechanical properties of fiber-reinforced 400 concretes at low-volume fraction, Construction and Building Materials, 73 (2014) 67-75.

57. L. Wang, J. Bao, B. Cheng, Influence of curing conditions on properties of normal and high strength concrete with and without pre-wetted lightweight aggregates, Journal of Advanced Concrete Technology, 15 (7) (2017) 300-313.

58. ACI 318, Building code requirements for structural concrete and commentary: ACI 318-99 and ACI 318R99, American Concrete Institute Committee 318, Farmington Hills, Michigan, (1999).

59. ASTM C33, Standard Specification for Concrete Aggregates (ASTM C33/C33M-11a), ASTM International, USA, 2011.

60. M.M. Khotbehsara, B.M. Miyandehi, F. Naseri, T. Ozbakkaloglu, F. Jafari, E. Mohseni, Effect of $\mathrm{SnO}_{2}$, $\mathrm{ZrO}_{2}$, and $\mathrm{CaCO}_{3}$ nanoparticles on water transport and durability properties of self-compacting mortar containing fly ash: Experimental observations and ANFIS predictions, Construction and Building Materials, 158 (2018) 823-834.

61. E. Mohseni, F. Naseri, R. Amjadi, M.M. Khotbehsara, M.M. Ranjbar, Microstructure and durability properties of cement mortars containing nano- $\mathrm{TiO}_{2}$ and rice husk ash, Construction and Building Materials, 114 (2016) 656664.

62. H. AzariJafari, M. Shekarchi, J. Berenjian, B. Ahmadi, Enhancing workability retention of concrete containing natural zeolite by superplasticizers' combination. Special Publication, 302 (2015) 416-424.

63. A. Hemmati, A. Kheyroddin, M. Sharbatdar, Y. Park, A. Abolmaali, Ductile behavior of high-performance fiber reinforced cementitious composite (HPFRCC) frames. Construction and Building Materials, 115 (2016) 681-689.

64. ASTM C39, Standard test method for compressive strength of cylindrical concrete specimens. West Conshohocken: ASTM International, (2011).

65. ASTM C496, Standard test method for splitting tensile strength of cylindrical concrete specimens. West Conshohocken: ASTM International, (2004).

66. ASTM C469, Standard test method for static modulus of elasticity and poisson's ratio of concrete in compression. West Conshohocken: ASTM International, (2002). 
67. NF EN 12390-13 AFNOR, Testing hardened concrete, in: Determination of secant modulus of elasticity in compression, (2013) 18-455.

68. M. Saberian, S. Jahandari, J. Li, F. Zivari, Effect of curing, capillary action, and groundwater level increment on geotechnical properties of lime concrete: Experimental and prediction studies, Journal of Rock Mechanics and Geotechnical Engineering, 9(4) (2017) 638-647.

69. S. Jahandari, M.M. Toufigh, J. Li, M. Saberian, Laboratory study of the effect of degrees of saturation on lime concrete resistance due to the groundwater level increment, Geotechnical and Geological Engineering, 36(1) (2018) 413-424.

70. S. Jahandari, Laboratory study of moisture and capillarity impact on lime concrete resistance due to the increase of ground water level. M.Sc. thesis, Faculty of Civil and Surveying Engineering, Department of Geotechnical Engineering, Graduate University of Advanced Technology, Kerman, Iran, 2015.

71. M. Hajforoush, R. Madandoust, M. Kazemi, Effects of simultaneous utilization of natural zeolite and magnetic water on engineering properties of self-compacting concrete, Asian Journal of Civil Engineering, 20(2) (2019) 289-300.

72. P.N. Balaguru, V. Ramakishan, Properties of fiber reinforced concrete: workability, behavior under longterm loading, air-void characteristics, ACI Materials Journal, 85 (3) (1988) 189-196.

73. R.F. Firestone, Radiation chemistry of water vapor; indirect effect on deuterium and exchange of D-atoms with water molecules, Journal of the American Chemical Society, 79(21) (1957) 5593-5598.

74. H. Mazaheripour, S. Ghanbarpour, S.H. Mirmoradi, I. Hosseinpour, The effect of polypropylene fibers on the properties of fresh and hardened lightweight selfcompacting concrete. Construction and Building Materials, 25 (2011) 351-358.

75. A. Kriker, G. Debicki, A. Bali, M.M.Khenfer, M.Chabannet, Mechanical properties of date palm fibres and concrete reinforced with date palm fibres in hot-dry climate, Cement and Concrete Composites, 27 (2005) 554-564.

76. P.L. Domone, A review of the hardened mechanical properties of self-compacting concrete, Cement \& Concrete Composites, 29(1) (2007) 1-12.

77. R. Madandoust, Strength assessment of lightweight concrete. PhD thesis, University of Liverpool, (1990).

78. FIP manual of lightweight aggregate concrete. Surry University Press, Glasgow and London, (1983).

79. F. Tomosawa, T. Noguchi, Relationship between compressive strength and modulus of elasticity of highstrength concrete, Proceedings of the third International Symposium on Utilization of High Strength Concrete, 2 (1993) 1247-1254. 